\title{
Evaluation of Temporary Ramp Metering for Work Zones
}

Final Report
November 2012

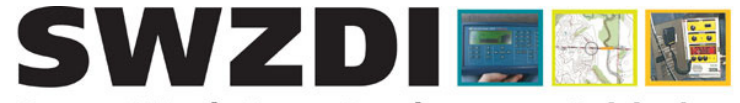

Smart Work Zone Deployment Initiative

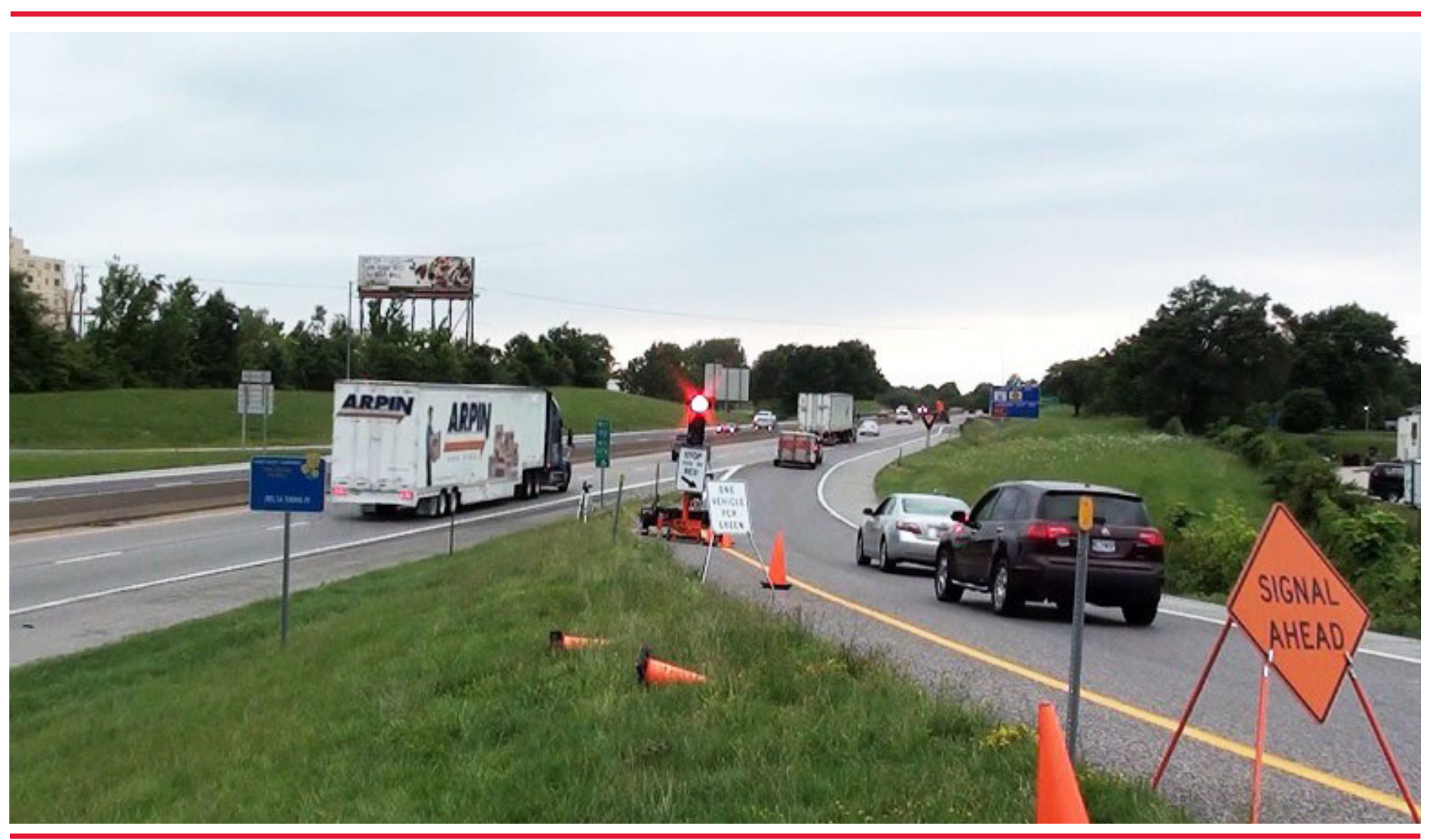

음izzou

University of Missouri - Columbia
Sponsored by

Smart Work Zone Deployment Initiative (TPF-5(081))

Federal Highway Administration

(InTrans Project 06-277) 


\begin{abstract}
About SWZDI
Iowa, Kansas, Missouri, and Nebraska created the Midwest States Smart Work Zone Deployment Initiative (SWZDI) in 1999 and Wisconsin joined in 2001. Through this pooled-fund study, researchers investigate better ways of controlling traffic through work zones. Their goal is to improve the safety and efficiency of traffic operations and highway work.
\end{abstract}

\title{
Disclaimer Notice
}

The contents of this report reflect the views of the authors, who are responsible for the facts and the accuracy of the information presented herein. The opinions, findings and conclusions expressed in this publication are those of the authors and not necessarily those of the sponsors.

The sponsors assume no liability for the contents or use of the information contained in this document. This report does not constitute a standard, specification, or regulation.

The sponsors do not endorse products or manufacturers. Trademarks or manufacturers' names appear in this report only because they are considered essential to the objective of the document.

\section{Non-Discrimination Statement}

Iowa State University does not discriminate on the basis of race, color, age, religion, national origin, sexual orientation, gender identity, genetic information, sex, marital status, disability, or status as a U.S. veteran. Inquiries can be directed to the Director of Equal Opportunity and Compliance, 3280 Beardshear Hall, (515) 294-7612.

\section{Iowa Department of Transportation Statements}

Federal and state laws prohibit employment and/or public accommodation discrimination on the basis of age, color, creed, disability, gender identity, national origin, pregnancy, race, religion, sex, sexual orientation or veteran's status. If you believe you have been discriminated against, please contact the Iowa Civil Rights Commission at 800-457-4416 or the Iowa Department of Transportation affirmative action officer. If you need accommodations because of a disability to access the Iowa Department of Transportation's services, contact the agency's affirmative action officer at 800-262-0003.

The preparation of this report was financed in part through funds provided by the Iowa Department of Transportation through its "Second Revised Agreement for the Management of Research Conducted by Iowa State University for the Iowa Department of Transportation" and its amendments.

The opinions, findings, and conclusions expressed in this publication are those of the authors and not necessarily those of the Iowa Department of Transportation or the U.S. Department of Transportation Federal Highway Administration. 
Technical Report Documentation Page

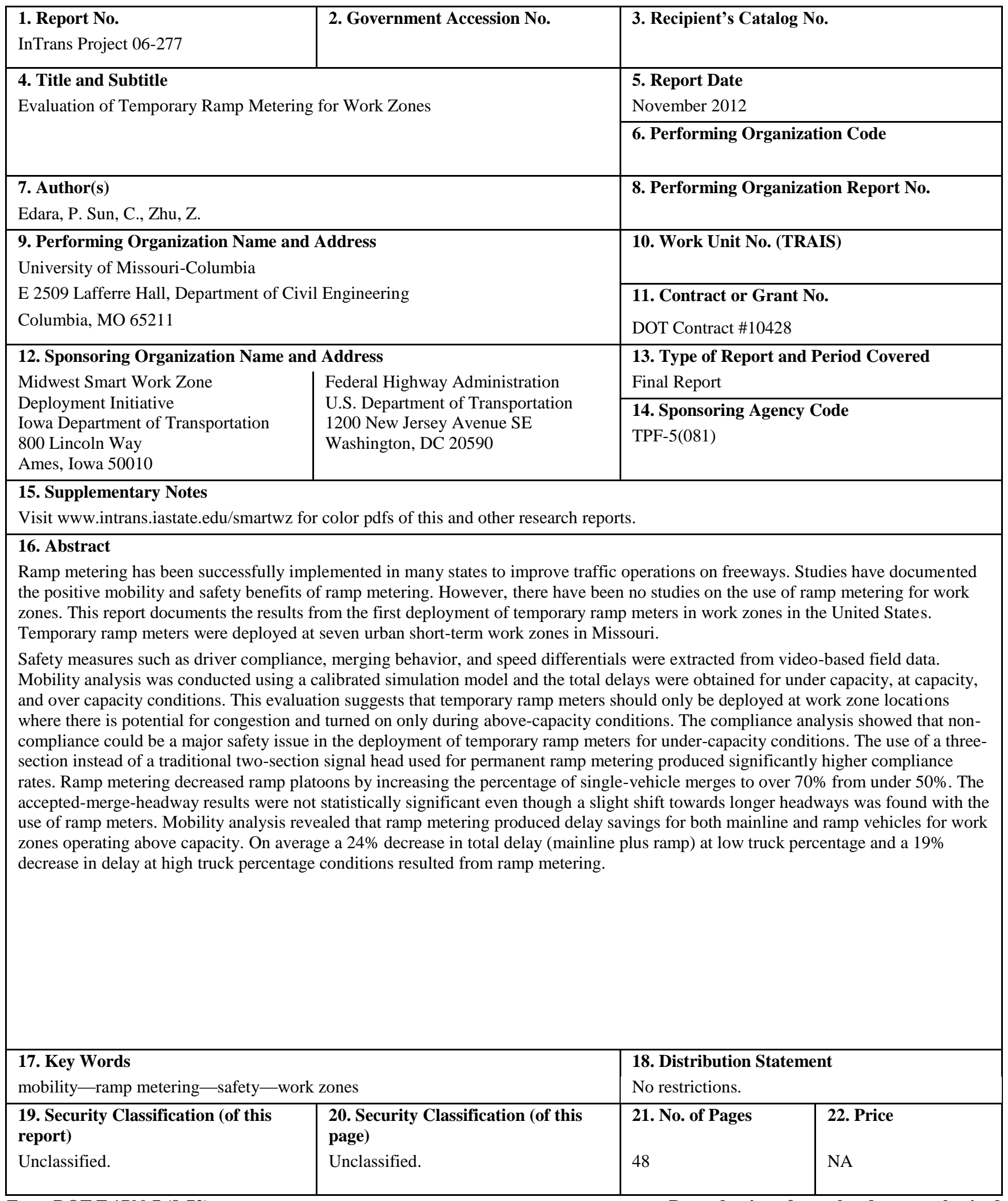

Form DOT F 1700.7 (8-72) 



\title{
EVALUATION OF TEMPORARY RAMP METERING FOR WORI ZONES
}

\author{
Final Report \\ November 2012
}

Praveen Edara, Ph.D., P.E., Assistant Professor

Carlos Sun, Ph.D., P.E., J.D., Associate Professor

Zhongyuan Zhu, Graduate Research Assistant

University of Missouri-Columbia

Department of Civil Engineering

E 2509 Lafferre Hall

Columbia, MO 65211

Sponsored by

the Midwest Smart Work Zone Deployment Initiative and

the Federal Highway Administration (FHWA) Pooled Fund Study TPF-5(081):

Iowa (lead state), Iowa, Kansas, Missouri, Nebraska, Wisconsin

Preparation of this report was financed in part through funds provided by the Iowa Department of Transportation through its Research Management Agreement with the Institute for Transportation

(InTrans Project 06-277)

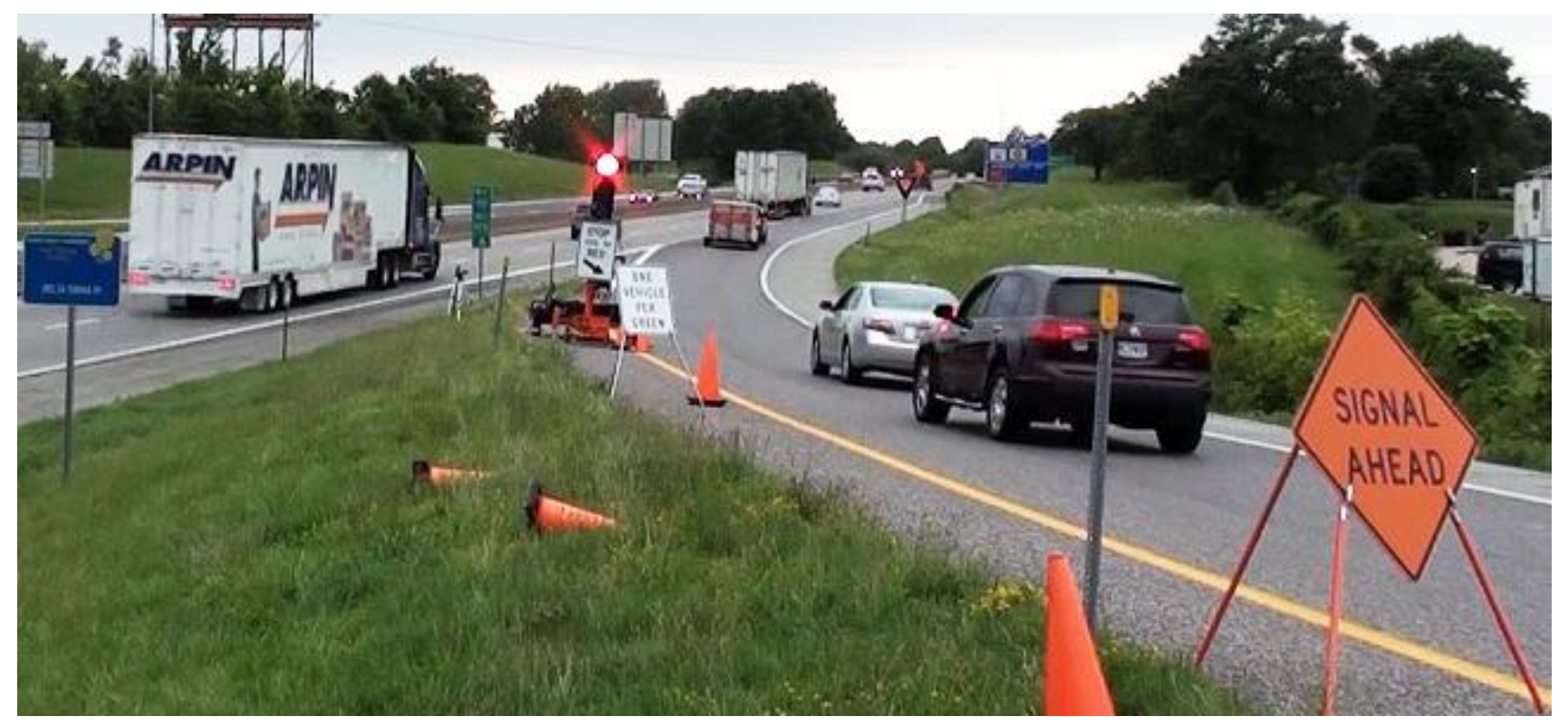





\section{TABLE OF CONTENTS}

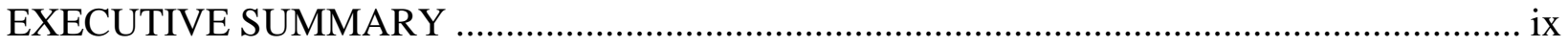

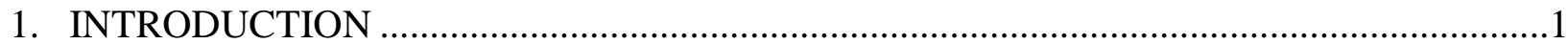

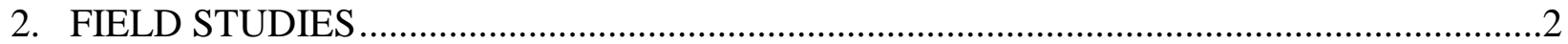

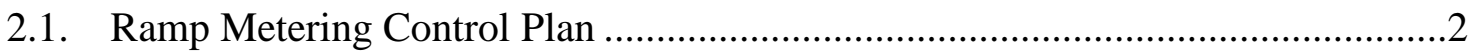

2.2. Field Site Descriptions ...............................................................................

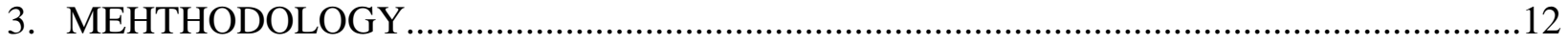

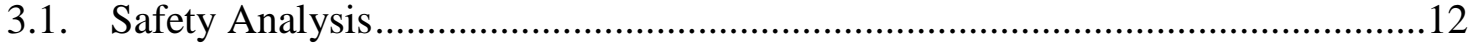

3.2. Mobility Analysis ........................................................................................14

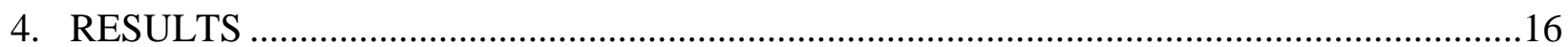

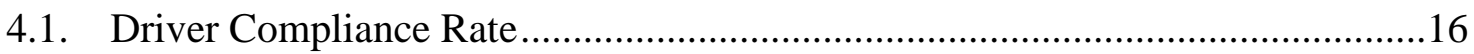

4.2. Effect of Temporary Ramp Meter on Speed ...................................................19

4.3. Measures Associated with Merge Point ............................................................29

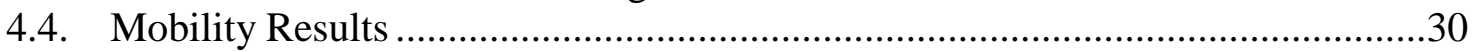

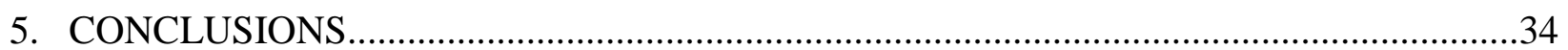

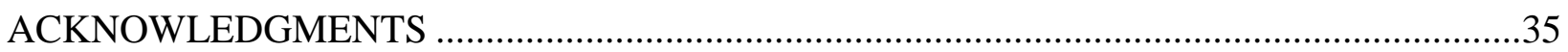

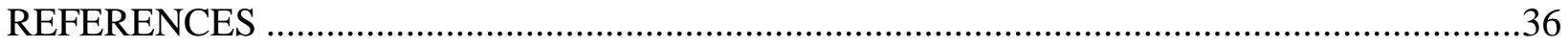




\section{LIST OF FIGURES}

Figure 1 Temporary ramp meter near a work zone............................................................ ix

Figure 2.1 Conceptual drawing of the temporary ramp meter...................................................... 3

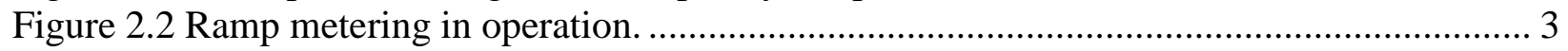

Figure 2.3 Temporary ramp metering field sites (Google maps 2012)...................................... 4

Figure 2.4 Work zone layout, I-70 WB at mile marker 131_...................................................... 6

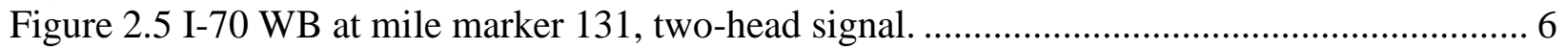

Figure 2.6 I-70 WB at mile marker 131, three-head signal. ...................................................... 7

Figure 2.7 Work zone layout, I-70 WB at mile marker 126.6 ................................................ 7

Figure 2.8 I-70 WB at mile marker 126.6 ....................................................................... 8

Figure 2.10 I-70 WB at mile marker 125.6.................................................................. 9

Figure 2.11 Work zone layout on I-70 EB at mile marker 129.0 ............................................ 9

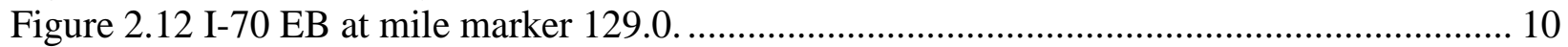

Figure 2.13 Work zone layout on US 63 NB at Stadium, left lane closed. ................................. 10

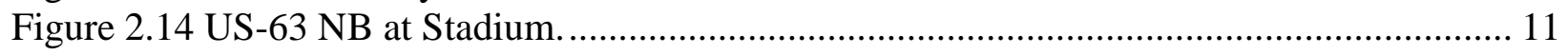

Figure 2.15 Work zone layout on US-63 at Stadium, right lane closed. ..................................... 11

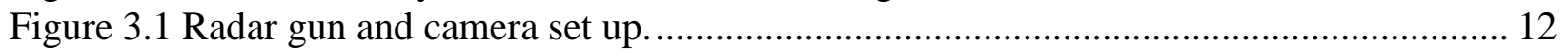

Figure 3.2 Mainline camera vision (left) and Ramp camera vision (right). ................................ 13

Figure 4.1 Cumulative distribution of speeds for the 'ramp between work zones' group............. 23

Figure 4.2 Merging headway cumulative distribution plot........................................................... 29

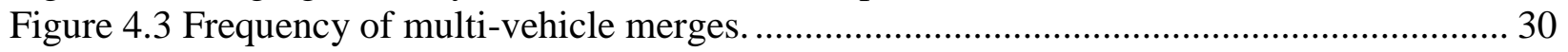




\section{LIST OF TABLES}

Table 1 Speed Measures for mainline and Ramp ……........................................................... $\mathrm{x}$

Table 2 Change in Total Delay Due to Ramp Metering ...........................................................

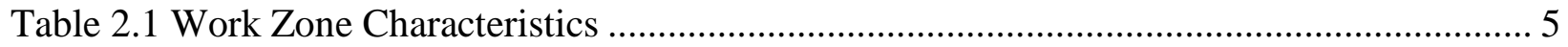

Table 4.1 Hypothesis Test for Compliance Rates.............................................................. 17

Table 4.2 Compliance Comparison of Platoon Condition vs. Free Flow Condition ...................... 17

Table 4.3 Commercial Vehicles, Congestion and WZ Type on Compliance ................................ 18

Table 4.4 WZ-Ramp Configurations on Compliance ……….................................................... 19

Table 4.5 Hypothesis Testing for Compliance across Configurations ........................................ 19

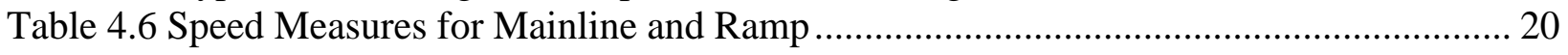

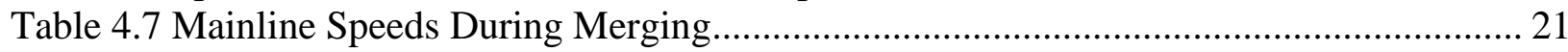

Table 4.8 Comparing Mainline Speeds with Metering for Classification I.................................. 21

Table 4.9 Comparing Mainline Speeds without Metering for Classification I.............................. 22

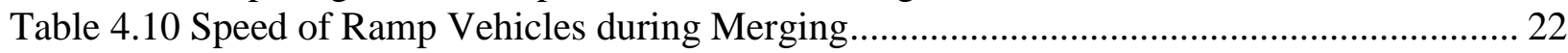

Table 4.11 Comparing Ramp Speeds with Metering for Classification I...................................... 23

Table 4.12 Comparing Ramp Speeds without Metering for Classification I................................ 23

Table 4.13 Speed Differentials for Classification I ................................................................. 24

Table 4.14 Comparing Speed Differentials with Metering for Classification I.............................. 24

Table 4.15 Comparing Speed Differentials without Metering for Classification I........................ 25

Table 4.16 Mainline Speeds during Merging for Classification II .............................................. 26

Table 4.17 Comparing Mainline Speeds with Metering for Classification II................................ 26

Table 4.18 Comparing Mainline Speeds without Metering for Classification II ......................... 26

Table 4.19 Speed of Ramp Vehicles during Merging for Classification II .................................. 27

Table 4.20 Comparing Ramp Speeds with Metering for Classification II ................................... 27

Table 4.21 Comparing Ramp Speeds without Metering for Classification II .............................. 27

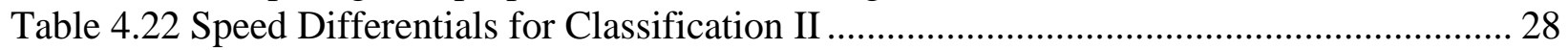

Table 4.23 Comparing Speed Differentials with Metering for Classification II ........................... 28

Table 4.24 Comparing Speed Differentials without Metering for Classification II ...................... 28

Table 4.25 Mainline and Ramp Delays with and without Ramp Meter for all Work Zones......... 31

Table 4.26 Change in Ramp Delay Due to Ramp Metering ........................................................ 32

Table 4.27 Change in Mainline Delay Due to Ramp Metering ...................................................... 32

Table 4.28 Change in Total Delay Due to Ramp Metering ........................................................ 33 



\section{EXECUTIVE SUMMARY}

Ramp metering has been implemented in several states with the main goal of improving the overall traffic efficiency by breaking up ramp platoons which results in smoother merges onto the mainline. It has been shown to produce shorter travel times and lower delays. Despite their documented efficiency and safety benefits, ramp metering has not been explored for work zones. This report adds to the work zone traffic control knowledge in three main ways. First, this is the first documented deployment of temporary ramp meters in work zones in the United States. Second, this report discusses safety, compliance, and mobility effects of temporary ramp metering. Third, unlike previous safety studies based on long term crash trends, the current study analyzes microscopic safety performance measures given the relatively short-term nature of work zones.

Ramp metering was deployed at seven different work zones in urban Columbia, Missouri, in 2011. These two-to-one lane closures were located near five different ramps on either I-70 or US-63, both being access-controlled high-speed facilities. The work zones differed in terms of work zone configuration, location of work zone with respect to the ramp, ramp volume, ramp grade and length, and truck percentage. Four video cameras and two speed radars were deployed at each location and documented details of critical locations such as the merging area and the ramp. The temporary ramp metering scheme was designed using guidance for permanent ramp meters from the MUTCD, Green Book, FHWA Ramp Metering Handbook and Missouri design practices. Figure 1 shows an example of a ramp meter involving a portable traffic signal and three static signs: "signal ahead", "one vehicle per green", and "stop here on red".

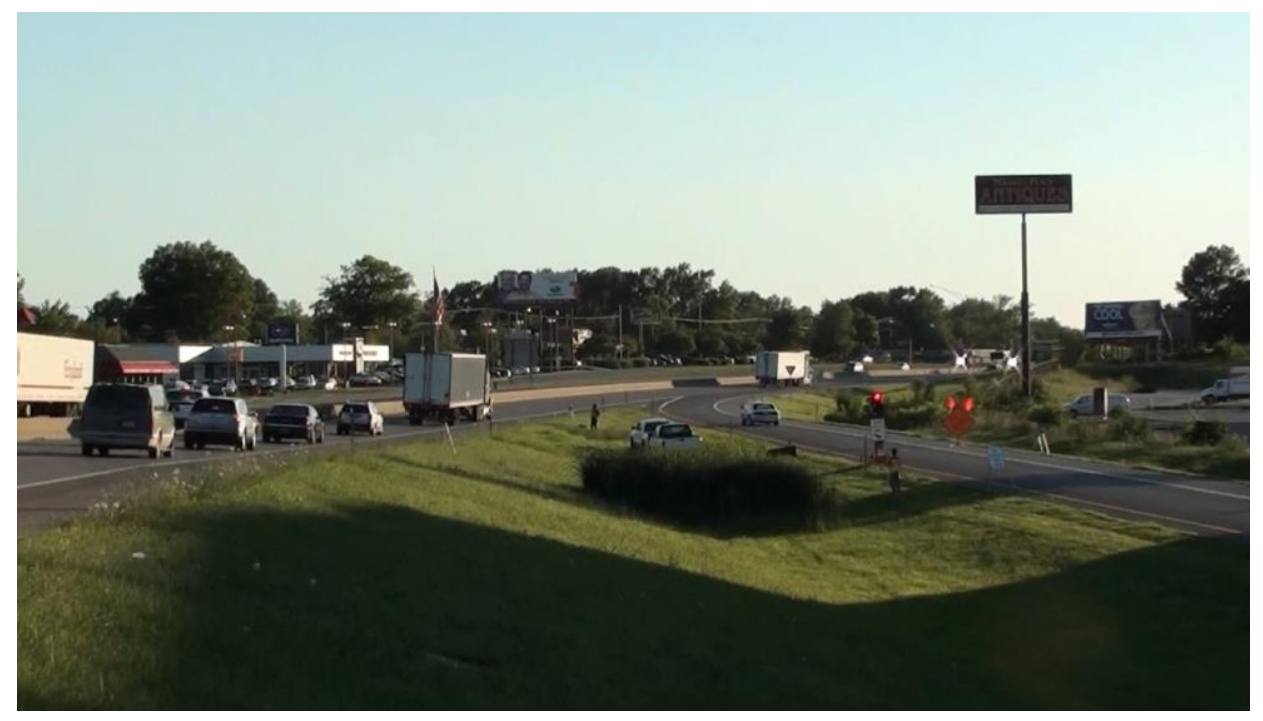

Figure 1 Temporary ramp meter near a work zone.

In terms of safety, temporary ramp meters were deployed for short periods of time, thus an adequate crash sample size could not be collected. Instead, the following surrogate safety measures were used: driver compliance rate, speed statistics of mainline and ramp, speed differentials between merging vehicles and mainline vehicles, ramp platoons, and merging headways. In terms of mobility, field-calibrated simulations were performed instead of direct field analysis; because the Missouri Department of Transportation (MoDOT) shifted to night 
work at congested locations, reducing over-capacity conditions. Simulation also had the ability of producing sensitivity and scenario analysis. The field calibration used microscopic measures of time headways and individual vehicle speeds.

One preliminary issue of the compliance study was the design of a signalization scheme that would work well for the work zones. Out of four different schemes, the 4R-1Y-2G (4 seconds of red, 1 of amber and 2 of green) resulted in the highest compliance rate and was used for all subsequent deployments. The three-section head was preferred over the two-section possibly because some drivers were unfamiliar with the two-head permanent ramp meters.

The compliance study showed that lack of compliance, at $63.6 \%$, could be a significant issue in the deployment of temporary ramp meters when ramps were under free-flow conditions. Thus ramp meters should be turned off during low ramp volumes. A platoon compliance effect was found, meaning that once a leading vehicle complied with the ramp meter, all subsequent vehicles also complied. Commercial vehicles were expected to have a higher compliance rate due to more training and regulations, but the rate was not statistically different from passenger vehicles. The interaction effect of commercial vehicles was also investigated by dividing the data into ramps that had no commercial vehicles and ramps that had commercial vehicle traffic. The overall compliance rate was $14.2 \%$ higher when there were commercial vehicles on ramps.

Table 1 shows the safety speed measures for the under-capacity conditions. The mainline-mean speeds decreased slightly by $2.58 \%$ with ramp meter operation, but the standard deviation increased by $29 \%$. The ramp-mean speeds decreased by $19.5 \%$ with ramp meter operation, and the standard deviation decreased by $11.6 \%$. The speed differentials between a merging vehicle and the leading and following vehicles on the mainline were significantly higher when the ramp meter was on. Leading speed differentials increased by $87.52 \%$ and following speed differentials increased by $98.67 \%$. Deploying during over-capacity conditions and on ramps with long ramp and acceleration lane lengths could avoid the mean speed decreases and large speed differentials found in this study.

Table 1 Speed Measures for mainline and Ramp

\begin{tabular}{|c|c|c|c|c|c|}
\hline & $\mathrm{N}$ & Mean, mph & Std. Dev., mph & Means, $\mathrm{p}$ & Variance, $\mathrm{p}$ \\
\hline \multicolumn{6}{|c|}{ Mainline Speed at Merge Point } \\
\hline Meter Off & 293 & 57.26 & 6.25 & \multirow{2}{*}{0.01} & \multirow{2}{*}{0.00} \\
\hline Meter On & 356 & 55.78 & 8.09 & & \\
\hline \multicolumn{6}{|c|}{ Ramp Speed at Merge Point } \\
\hline Meter Off & 385 & 46.88 & 5.95 & \multirow{2}{*}{0.00} & \multirow{2}{*}{0.07} \\
\hline Meter On & 409 & 37.74 & 5.26 & & \\
\hline \multicolumn{6}{|c|}{ Speed Differentials } \\
\hline & N, Lead/Follow & $\begin{array}{c}\text { Lead, Mean, } \\
\text { mph }\end{array}$ & Follow, Mean, mph & $\begin{array}{c}\text { Lead } \\
\text { Means, } p\end{array}$ & $\begin{array}{c}\text { Follow } \\
\text { Means, p }\end{array}$ \\
\hline Meter Off & $164 / 153$ & -10.34 & -9.78 & \multirow{2}{*}{0.00} & \multirow{2}{*}{0.00} \\
\hline Meter On & $185 / 149$ & -19.39 & -19.43 & & \\
\hline
\end{tabular}

Ramp metering decreased ramp platoons by increasing the percentage of single-vehicle merges to over $70 \%$ from under $50 \%$. The breaking up of ramp platoons reduces mainline traffic disruptions thus improving both safety and efficiency. The accepted-merge-headway results were 
not statistically significant even though a slight shift towards longer headways was found with the use of ramp meters.

The amount of delay experienced by mainline and ramp vehicles with and without ramp meter were obtained from field-calibrated simulations and shown in Table 2. For under-capacity conditions, ramp metering increased total delay by $42 \%$ to $50 \%$. The percentage delay increase for ramp traffic was about three times that of the mainline. For above-capacity conditions, ramp metering decreased total delays between $19 \%$ and $24 \%$. The delay benefits were exhibited at all five work zones.

Table 2 Change in Total Delay Due to Ramp Metering

\begin{tabular}{|c|c|c|c|}
\hline & Total volume (mainline + ramp) & Truck \% & $\%$ Total Delay Change \\
\hline \multirow{2}{*}{ Under capacity } & \multirow{2}{*}{$900(650+250)$} & Low $(10 \%)$ & $50 \%$ \\
\hline & & High $(40 \%)$ & $42 \%$ \\
\hline \multirow{2}{*}{ At Capacity } & \multirow{2}{*}{$1240(900+340)$} & Low $(10 \%)$ & $27 \%$ \\
\hline & & High $(40 \%)$ & $6 \%$ \\
\hline \multirow{2}{*}{ Above capacity } & \multirow{2}{*}{$1754(1240+514)$} & Low $(10 \%)$ & $-24 \%$ \\
\hline & & High $(40 \%)$ & $-19 \%$ \\
\hline
\end{tabular}

In conclusion, this study suggests that temporary ramp meters should only be deployed at locations where there is potential for congestion and turned on only during above-capacity conditions. The drawbacks outweigh the minor benefits when the ramp meter is used during noncongested conditions. The compliance analysis showed that non-compliance could be a safety concern if deployed during under-capacity conditions. The use of a three-section instead of a traditional two-section signal head produced significantly higher compliance rates and is recommended for work zones. Mobility analysis showed that ramp metering produced delay savings for both mainline and ramp vehicles for work zones operating above capacity. For other conditions ramp metering actually increases the total delay. Because this was the first field deployment of temporary ramp meters, MoDOT had concerns about deployment in highly congested areas. Future research could add to the existing study by including highly congested field sites. 



\section{INTRODUCTION}

Ramp metering has been implemented in the United States since the 1960s (1) with the main goal of improving the overall efficiency of a highway system by regulating the traffic entering the mainline. It has been implemented in states such as California, Minnesota, Texas and Florida and shown to produce operational benefits in terms of shorter travel times and lower delays. Cambridge Systematics (2) evaluated ramp meters in the Twin Cities for the Minnesota Department of Transportation. The field data collection consisted of two weeks of "with" ramp meters and two weeks of "without" ramp meters. The study found that ramp metering improved efficiency by increasing speeds and the flow rate on the mainline while reducing travel times for long distance trips. A 26 percent increase in the total number of crashes was also reported after ramp meters were deactivated. A follow-up study (3) reported a 15 percent increase in total number of crashes during peak hours compared to historical data. Similar efficiency improvements resulting from ramp metering were reported in other states. Research on the safety impacts of ramp metering is sparse. The limited safety literature involving aggregate crash analysis $(2,3)$ and microscopic simulation $(4,5,6,7)$ reported positive safety benefits of ramp metering.

Despite their documented efficiency and safety benefits, ramp metering strategies have not been explored for work zones. There are no published studies that report on the use of ramp metering in work zones. This report presents the results of temporary ramp metering deployment for work zones. The study explored the safety and mobility impacts.

The report adds to the existing ramp metering and work zone traffic control knowledge in three main ways. First and foremost, this report presents the results from the first deployment of temporary ramp meters in work zones in the United States. Second, this report discusses safety, compliance, and mobility effects of temporary ramp metering. Third, unlike previous safety studies, the current study analyzes microscopic safety performance measures since long term crash data is not available. This report informs state transportation agencies about the potential benefits and drawbacks of temporary ramp metering in work zones. 


\section{FIELD STUDIES}

\subsection{Ramp Metering Control Plan}

The temporary ramp meter hardware used in this study was a portable traffic signal that was battery-powered and could be controlled via a remote control. The remote control feature was important in case the meter needed to be turned off in an emergency, or to set the meter to green to prevent spillback. The three-head signal could be configured as a two-head signal by re-wiring and eliminating the amber head.

According to the MUTCD section on entrance ramp control signals, an engineering study should precede the installation of ramp control signals (8). The study involved the collection of preliminary ramp volumes to determine the potential for queue spillback and to design a metering rate, the analysis of site geometrics to determine the optimum meter location, the review of regional traffic demand, and the inspection of work zone projects in the region. Permanent ramp meters that were deployed in the state in Kansas City were also examined and used as a template. Three major references, the MUTCD (8), the FHWA handbook (9) and the Green Book (10), were used in the development of the temporary ramp metering plan. Figure 2.1 is a conceptual diagram, and Figure 2.2 is an example of the plan deployed at a work zone on I70 in Columbia, Missouri. Both figures show the MUTCD specified sequence of signage: "signal ahead" used in place of "ramp meter ahead"; "one vehicle per green"; and "stop here on red" just below the signal head. The height of the signal was extended between 4.5 and 6 feet from the pavement to the bottom of the signal housing according to the MUTCD. Because the ramp meter was deployed near a work zone, the temporary traffic control sections of the MUTCD also applied. Thus the researchers monitored queues closely in real-time to prevent spillover onto arterial streets. The ramp meters were placed in a location in order to strike a balance between queue storage and acceleration distance to the freeway. The acceleration distances were computed using Green Book standards. 


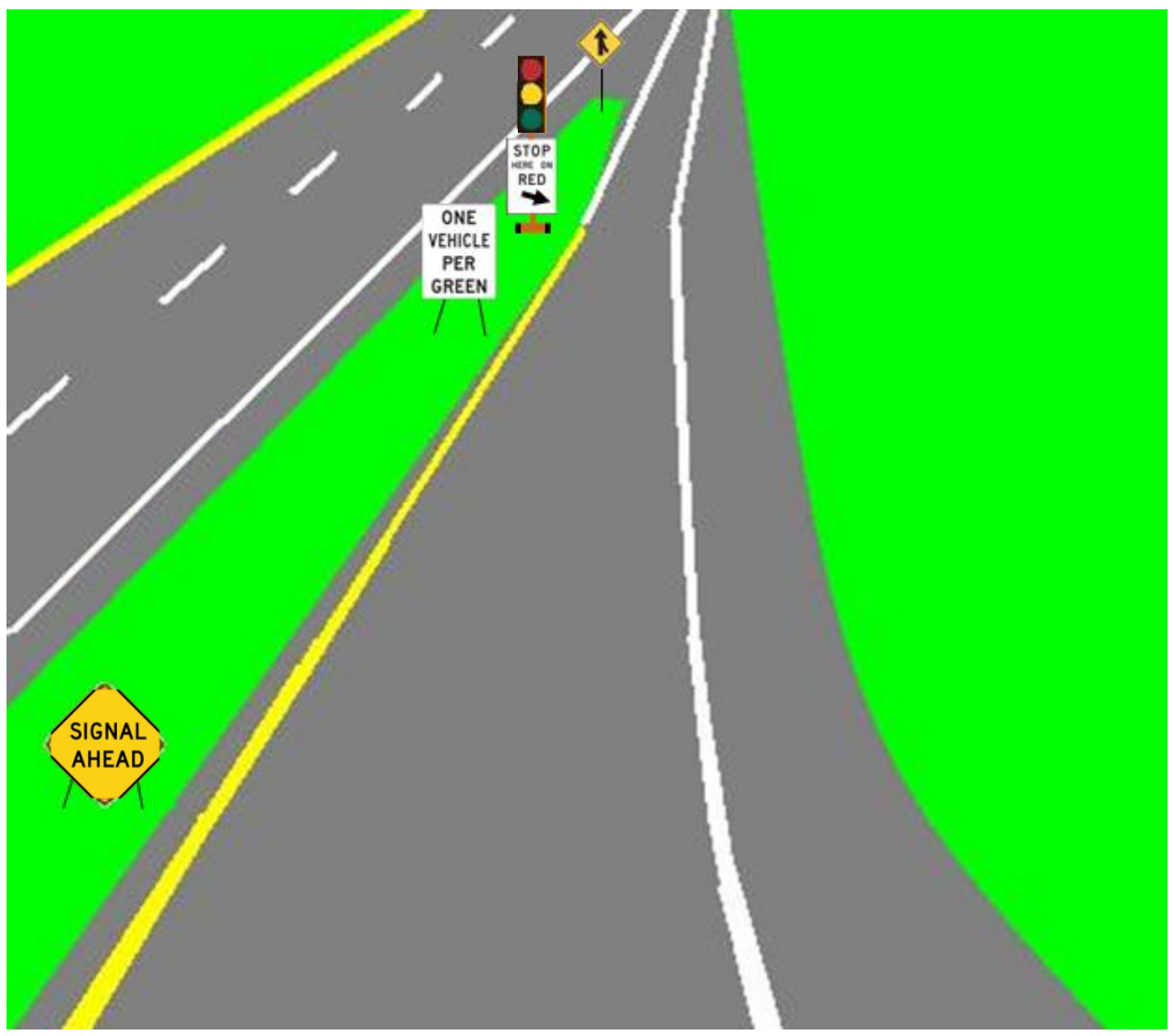

Figure 2.1 Conceptual drawing of the temporary ramp meter.

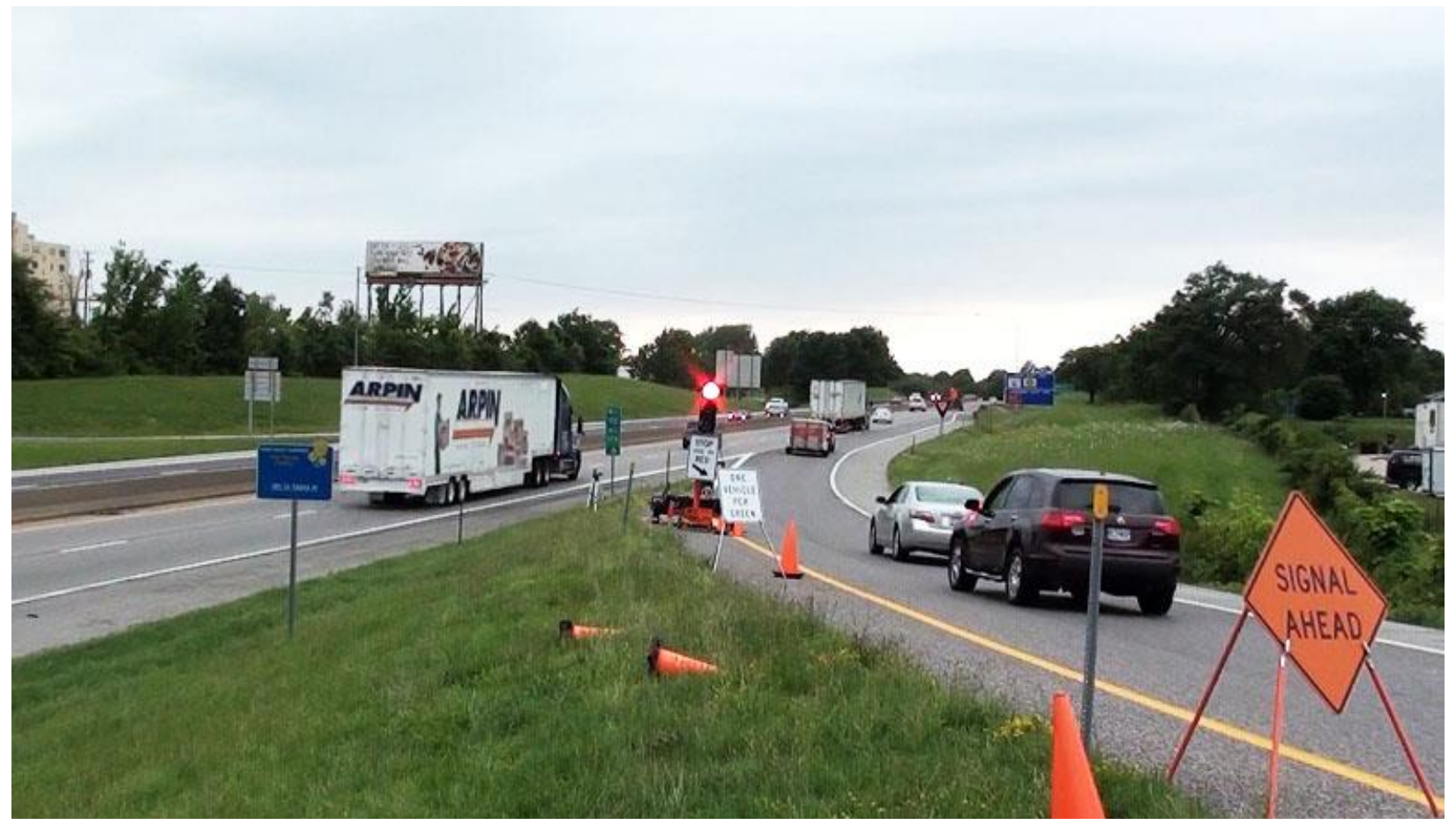

Figure 2.2 Ramp metering in operation. 


\subsection{Field Site Descriptions}

Ramp metering was deployed at seven different work zones in Columbia, Missouri, during June and July, 2011. These work zones were deployed near five different ramps as shown in Figure 2.3. These locations were all within the same urban metropolitan area and involved the same driver population. The work zones were located on either Interstate 70 or U.S. Highway 63, both of which are access-controlled high speed facilities. All the work zones involved a two-to-one lane closure. These work zones differed in terms of work zone configuration, location of work zone with respect to the ramp, ramp volume, entrance ramp grade and length, and truck percentage. Table 2.1 shows the characteristics of each work zone. Work Zone 5 had the highest ramp volume as well as an $8 \%$ truck volume on the ramp. It was also unique in that the ramp was in between two active work zones. Work zones 1 and 2 preceded the ramp. All other work zones were located after the ramp. All the two-to-one lane closures involved the right lane except for Work Zone 6. Work zones 1, 2, 3, and 5 had downhill ramps, while work zones 4, 6, and 7 had uphill ramps which made acceleration more difficult. The ramp length was measured to the gore point, and Work Zone 3 had a particularly short ramp. The short ramp meant less queue storage; thus it was monitored carefully for spill-back. The distance from the ramp meter to the gore point is shown in the last row.

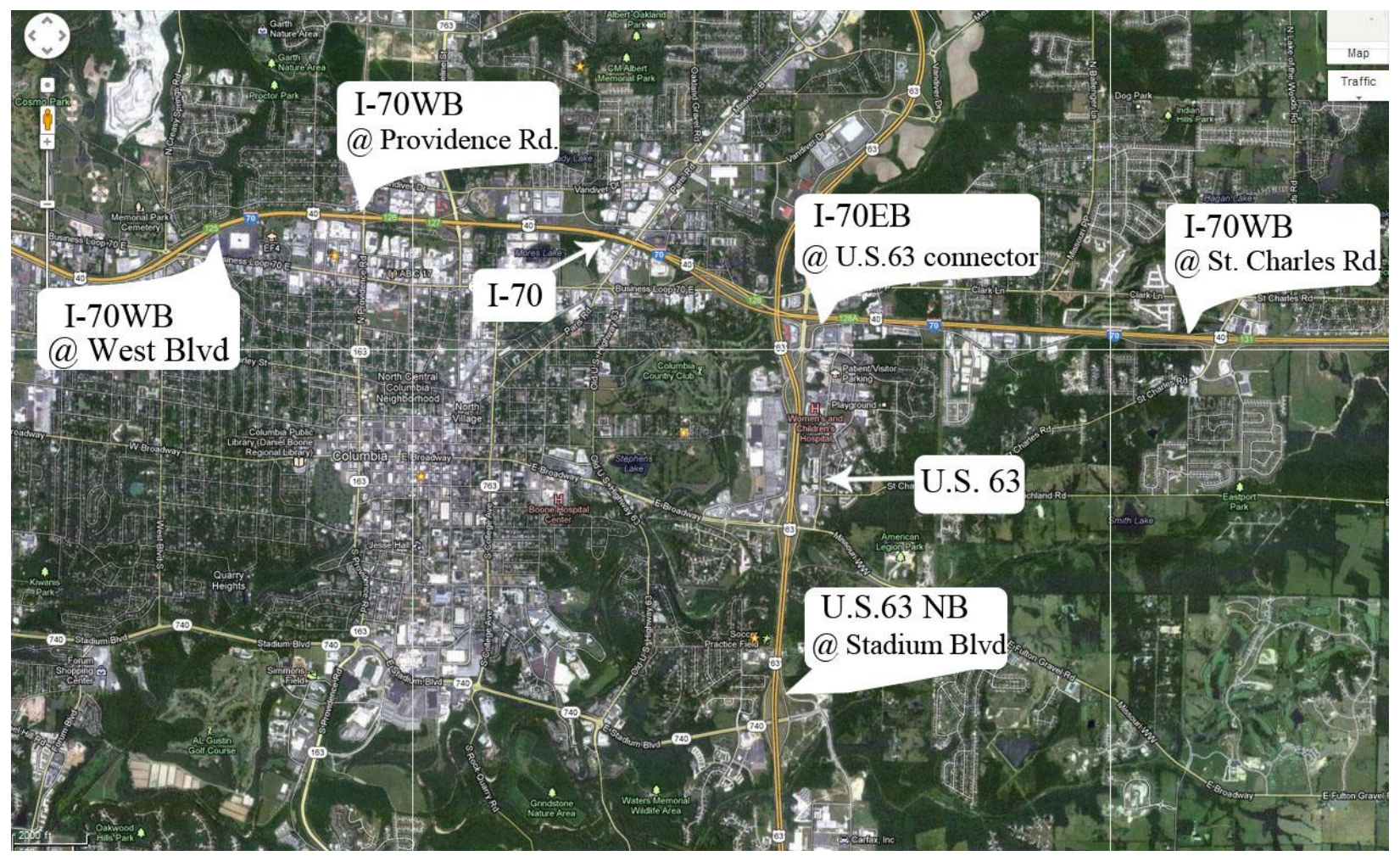

Figure 2.3 Temporary ramp metering field sites (Google maps 2012). 
Table 2.1 Work Zone Characteristics

\begin{tabular}{|c|c|c|c|c|c|c|c|}
\hline \multirow{2}{*}{ Characteristic } & \multicolumn{7}{|c|}{ Work Zone } \\
\cline { 2 - 8 } & 1 & 2 & 3 & 4 & 5 & 6 & 7 \\
\hline Facility & I-70 & I-70 & I-70 & I-70 & I-70 & US-63 & US-63 \\
\hline Exit & St. Char. & St. Char. & Prov. & West & US-63 & Stad. & Stad. \\
\hline Date & $6 / 19$ & $6 / 20$ & $6 / 27$ & $6 / 28$ & $7 / 11$ & $7 / 12$ & $7 / 13$ \\
\hline Ramp Vol., & 146 & 211 & 137 & 55 & 328 & 222 & 211 \\
veh/hour & Right & Right & Right & Right & Right & Left & Right \\
\hline $\begin{array}{c}\text { Lane Closed } \\
\text { Ramp Locat. }\end{array}$ & After & After & Before & Before & Between & Before & Before \\
\hline Ramp Truck\% & $0 \%$ & $0 \%$ & $0 \%$ & $0 \%$ & $8 \%$ & $2.1 \%$ & $1 \%$ \\
\hline Grade & $-5.7 \%$ & $-5.7 \%$ & $-2.4 \%$ & $1.7 \%$ & $-0.5 \%$ & $2.6 \%$ & $2.6 \%$ \\
\hline Ramp Len., ft & 963 & 963 & 490 & 1113 & 1120 & 1220 & 1220 \\
\hline Meter-Gore, ft & 471 & 471 & 240 & 632 & 493 & 351 & 351 \\
\hline
\end{tabular}

For each site two figures are presented next: a layout of the work zone and a picture of the ramp meter in operation at the site. The layout illustrates the location of the ramp meter with respect to the gore point as was shown in Table 2.1. The picture shows the grade and the general geometrics of the ramp area. Figures 2.5 and 2.6 show two different signal configurations that were deployed near the mile marker-131 ramp on I-70: two-head and three-head. Figures 2.13 and 2.15 show the two different types of lane closure, left and right, on US-63 at Stadium Boulevard. 


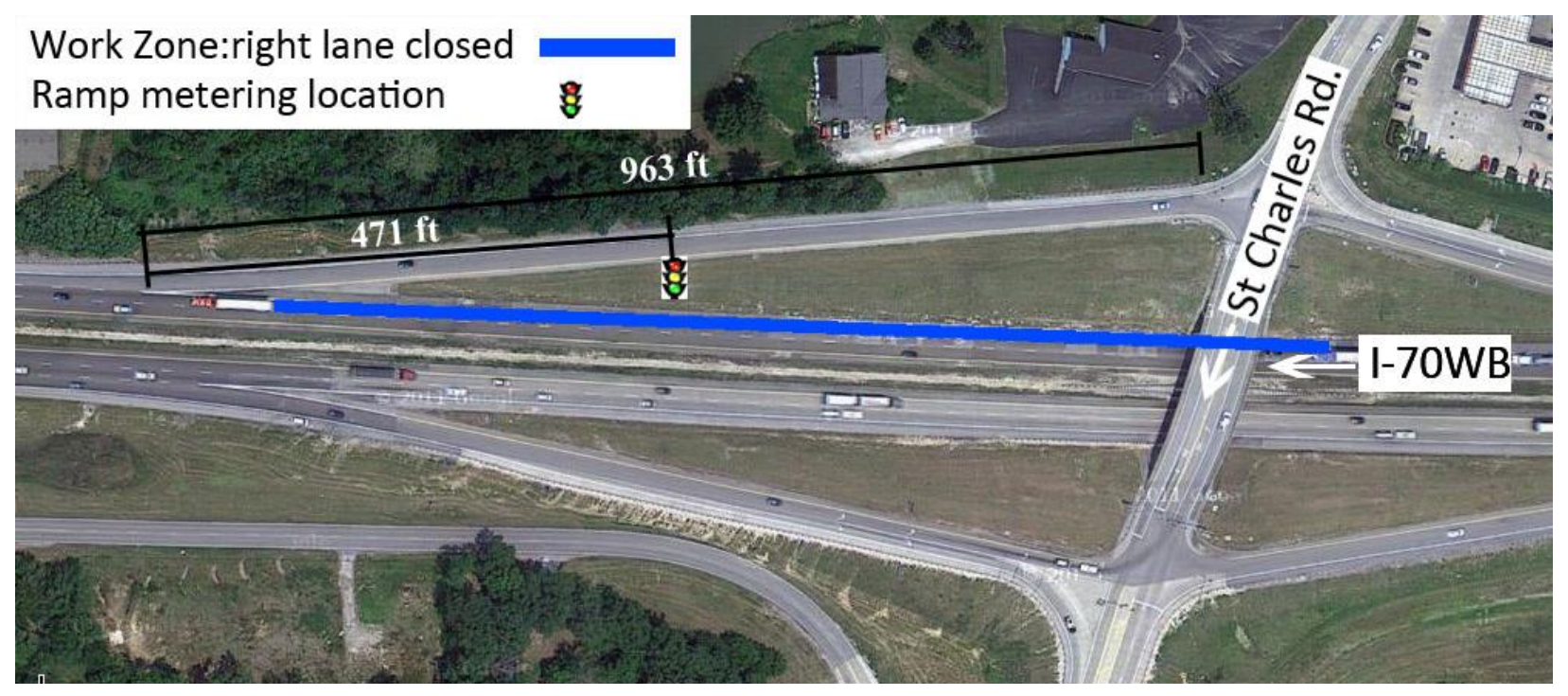

Figure 2.4 Work zone layout, I-70 WB at mile marker 131.

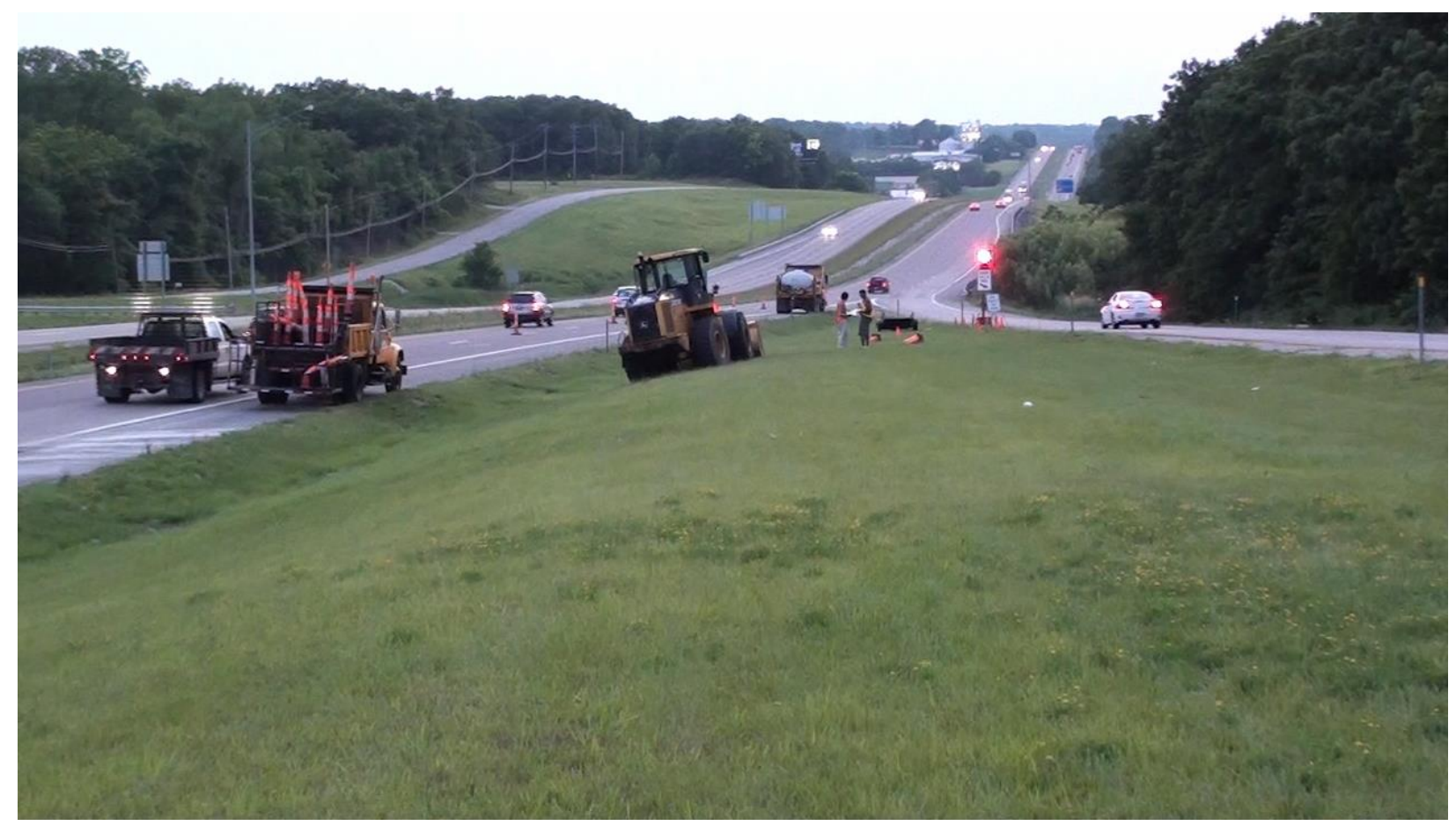

Figure 2.5 I-70 WB at mile marker 131, two-head signal. 


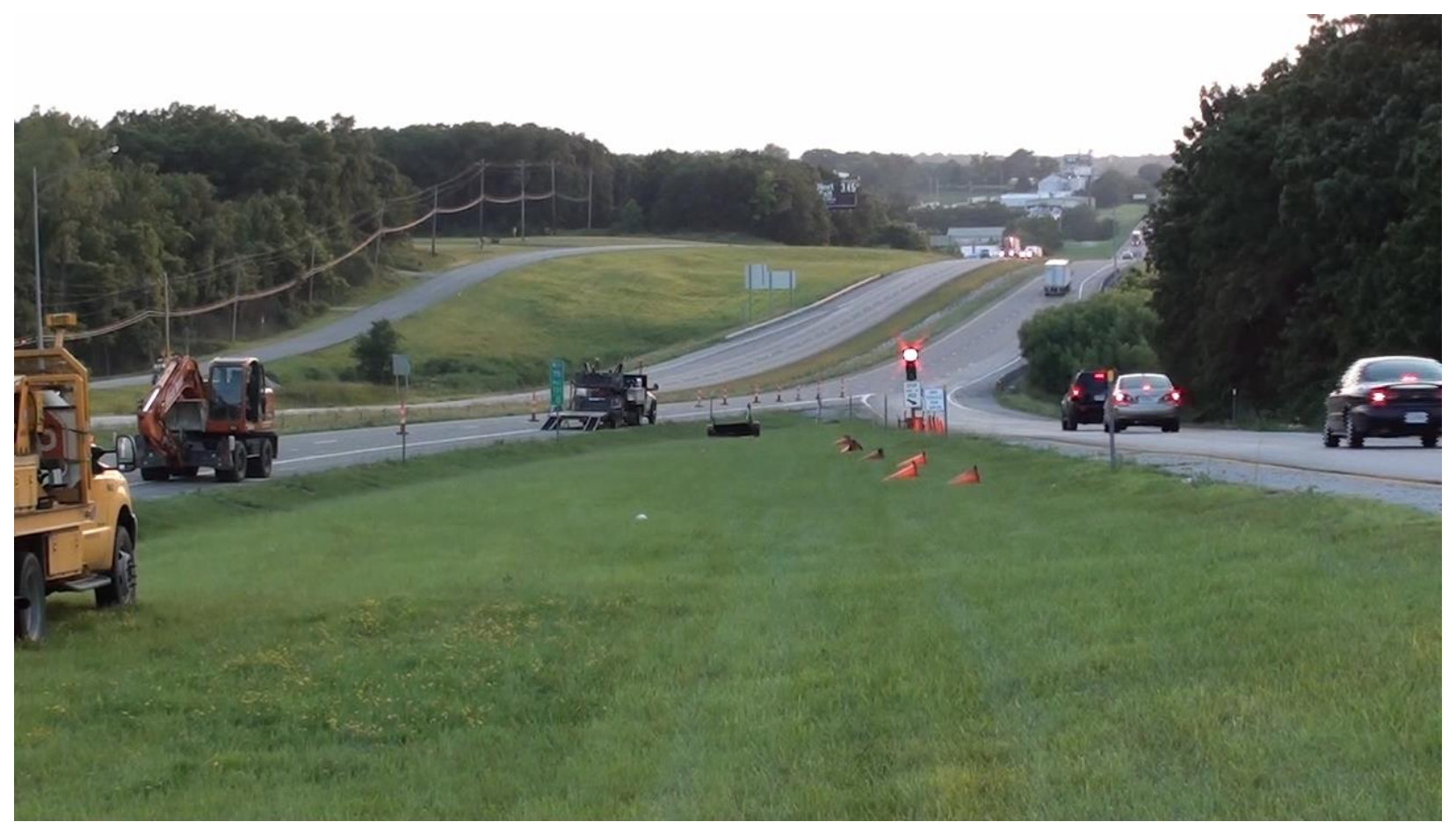

Figure 2.6 I-70 WB at mile marker 131, three-head signal.

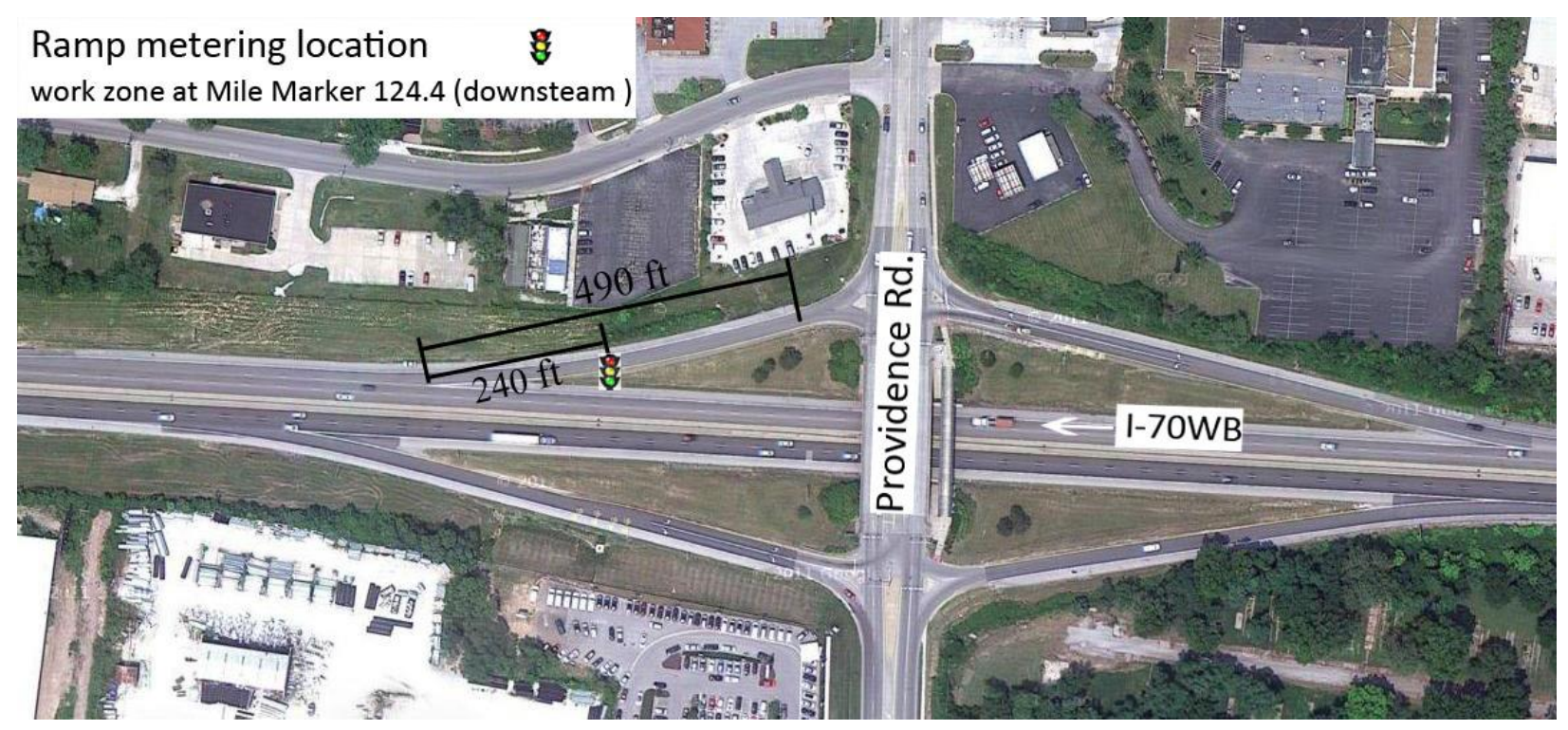

Figure 2.7 Work zone layout, I-70 WB at mile marker 126.6. 


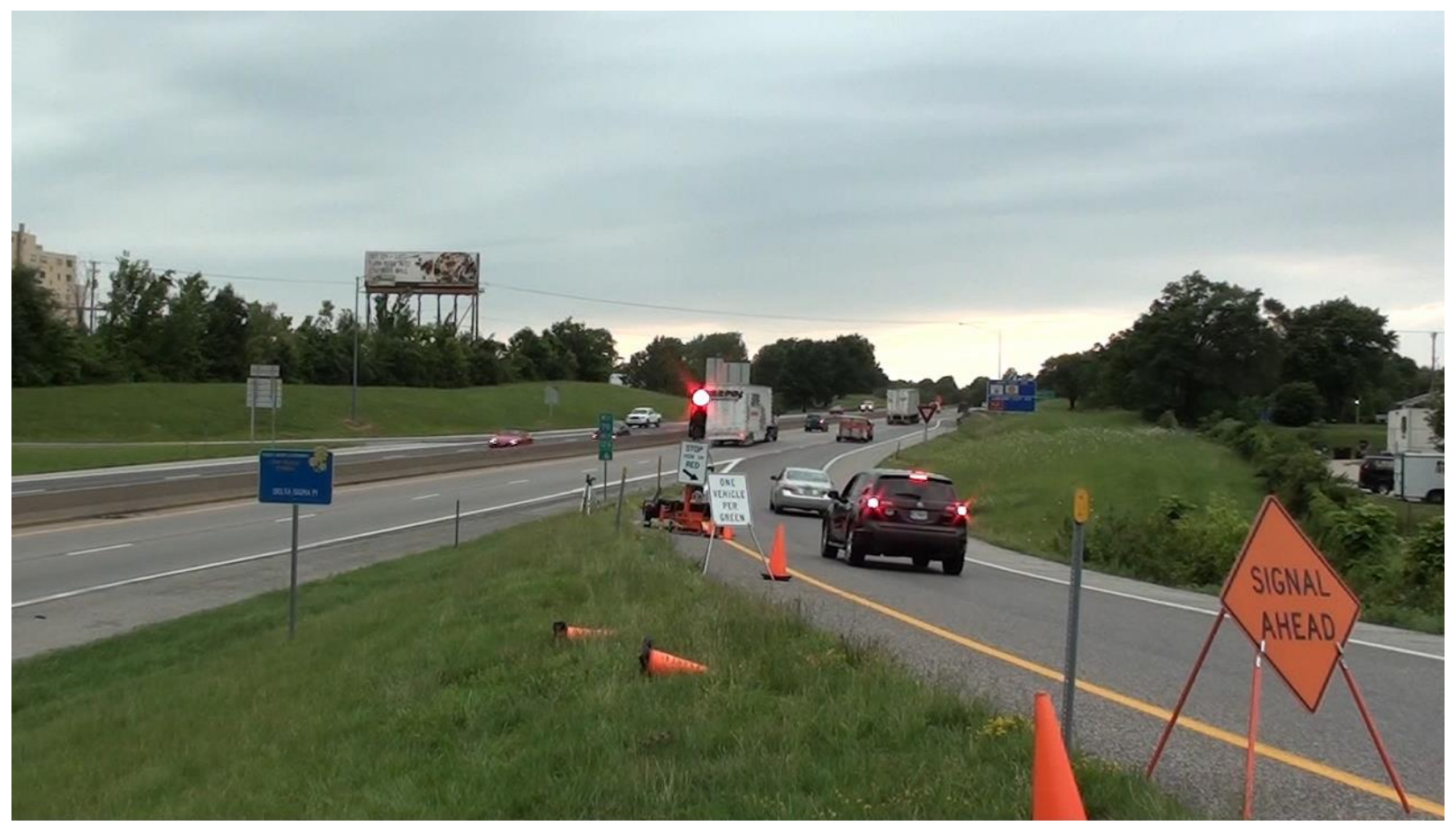

Figure 2.8 I-70 WB at mile marker 126.6.

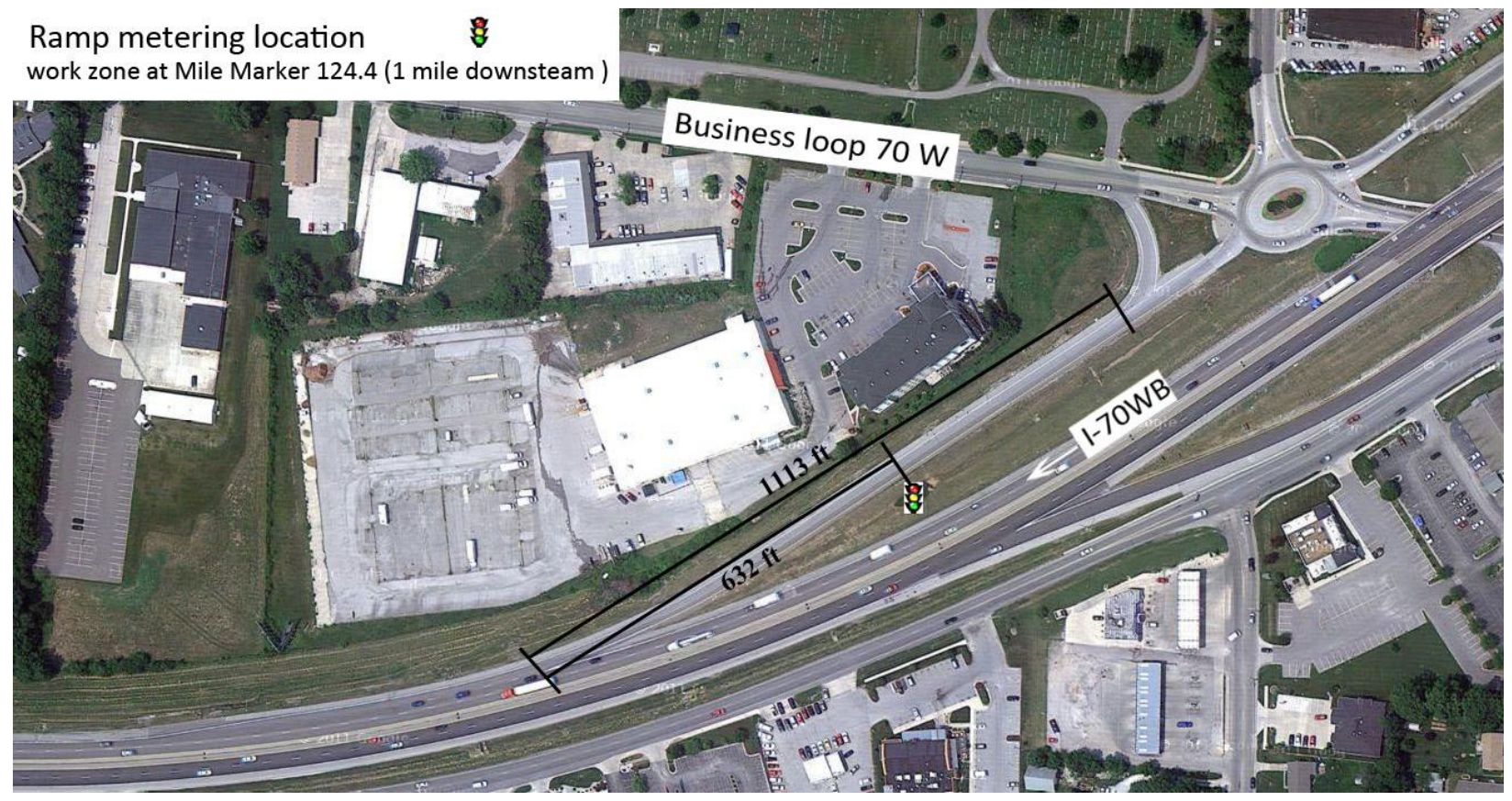

Figure 2.9 Work zone layout on I-70 WB at mile marker 125.6. 


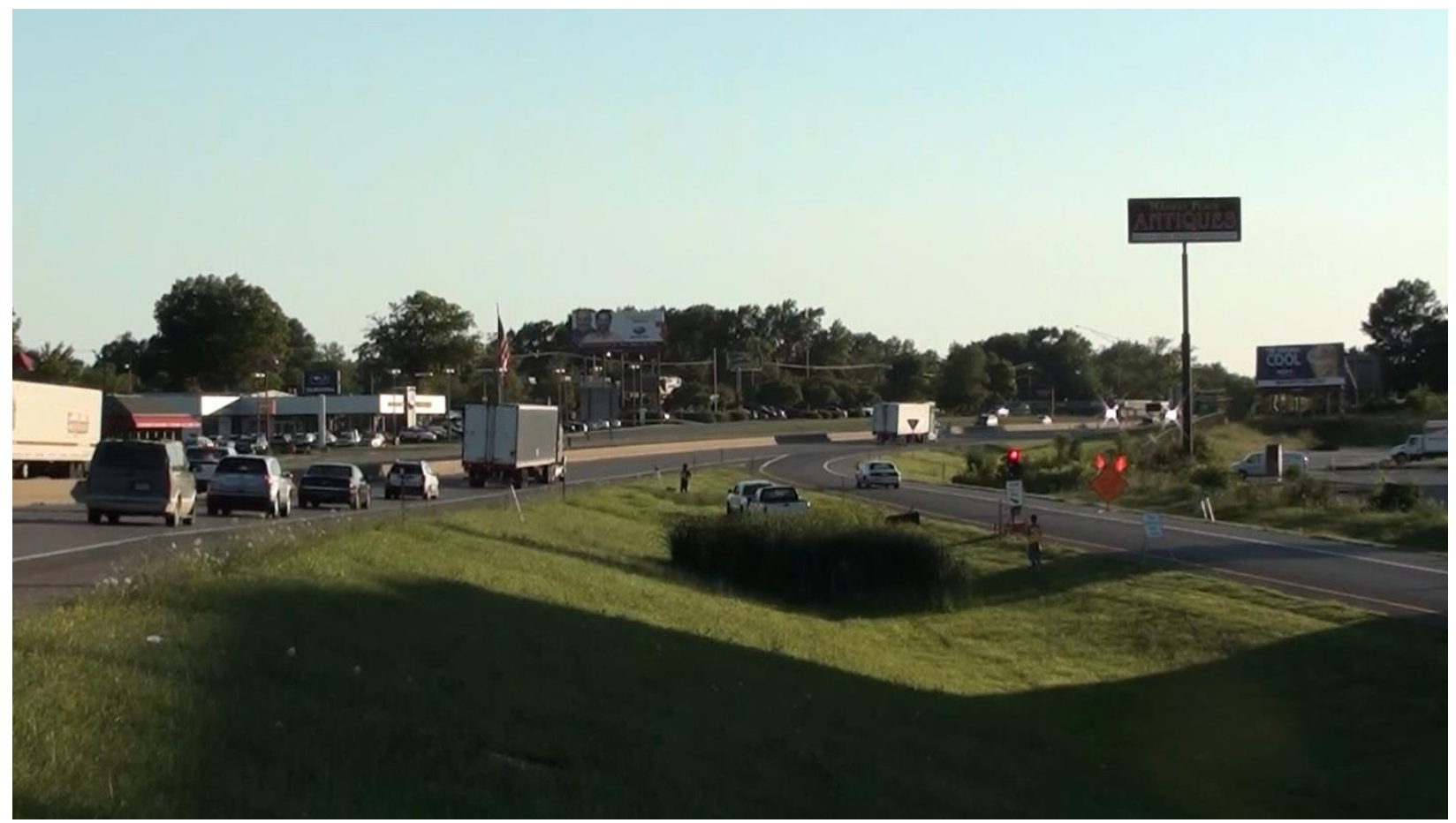

Figure 2.10 I-70 WB at mile marker 125.6.

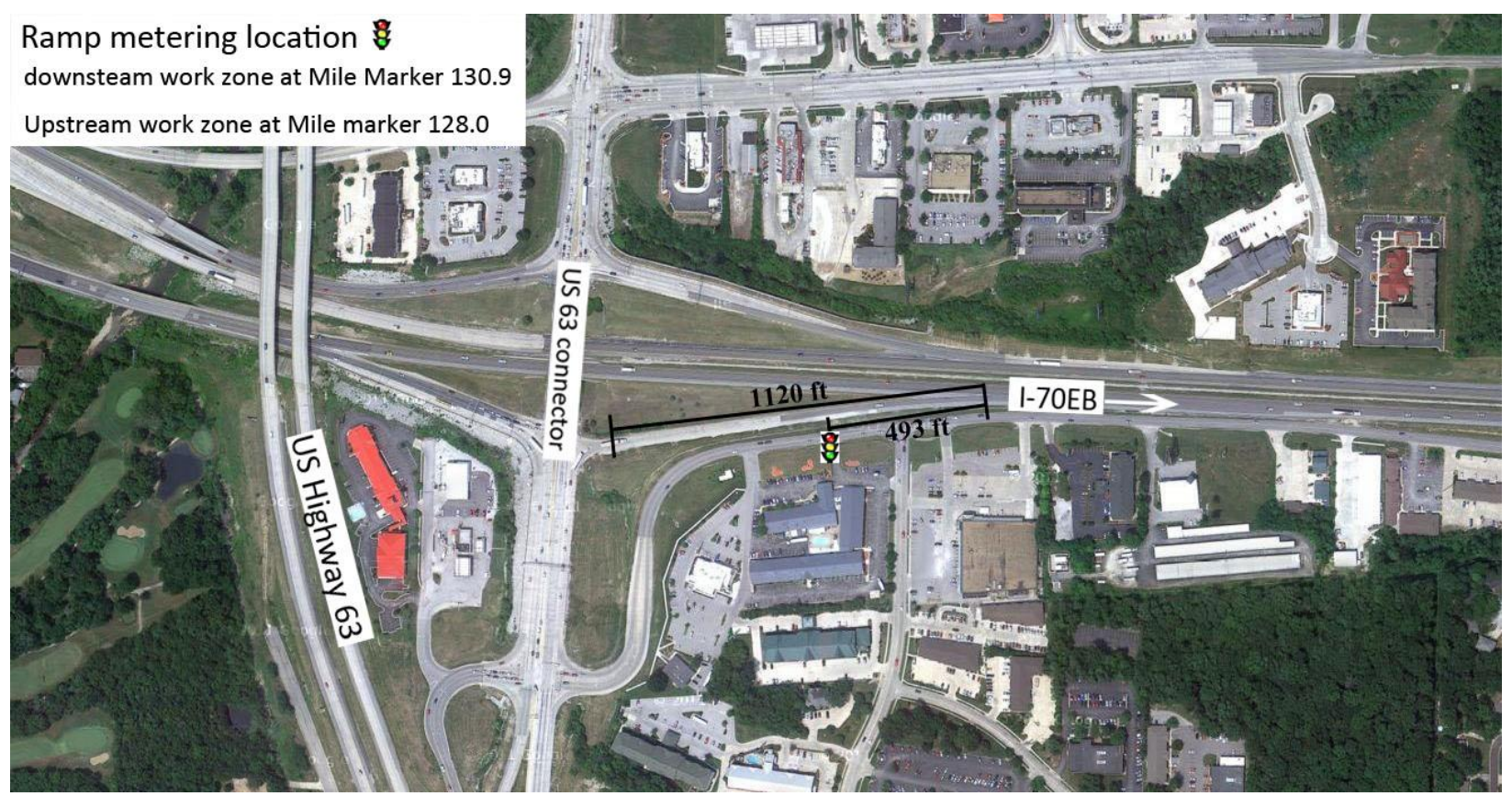

Figure 2.11 Work zone layout on I-70 EB at mile marker 129.0. 


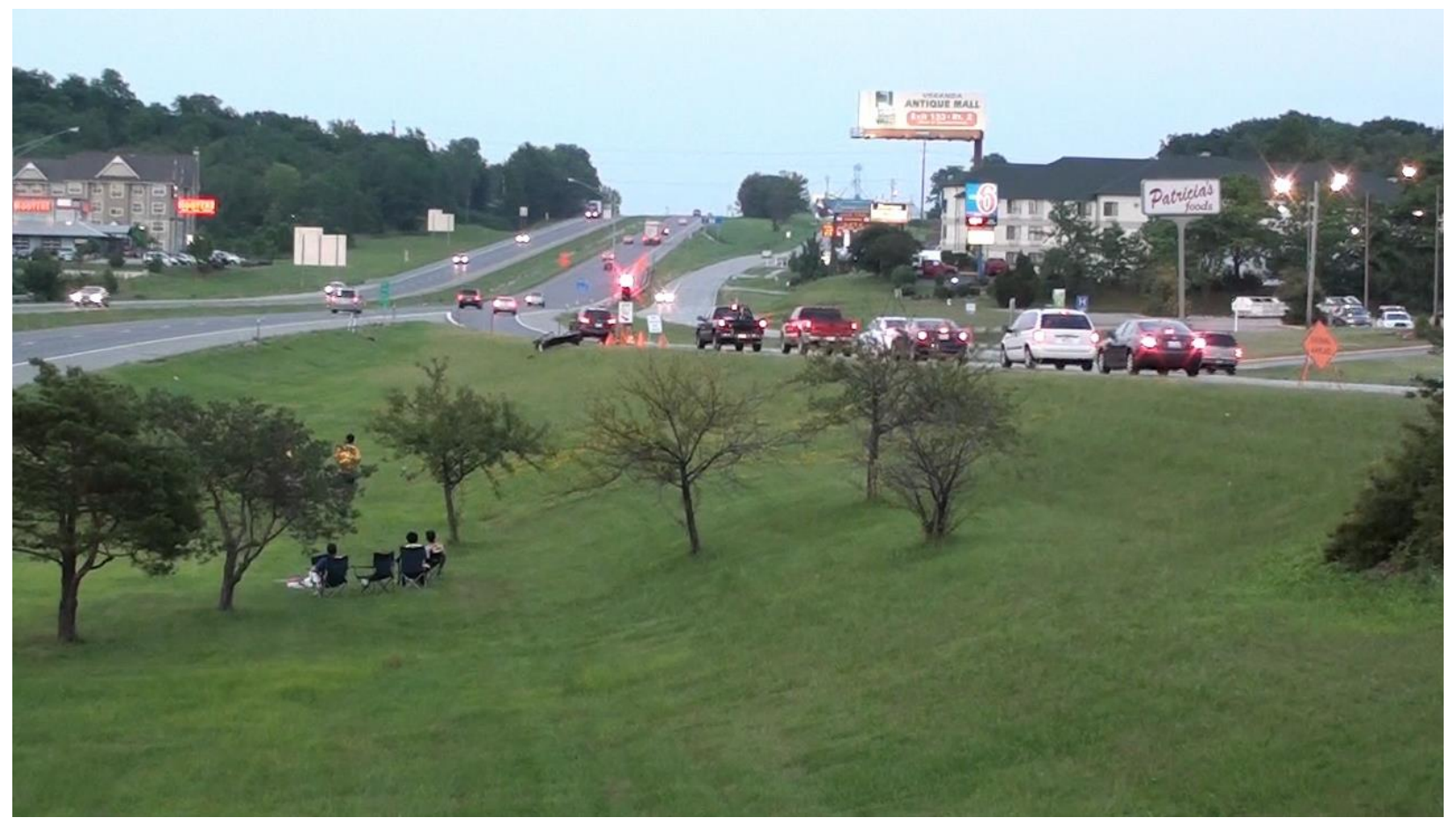

Figure 2.12 I-70 EB at mile marker 129.0.

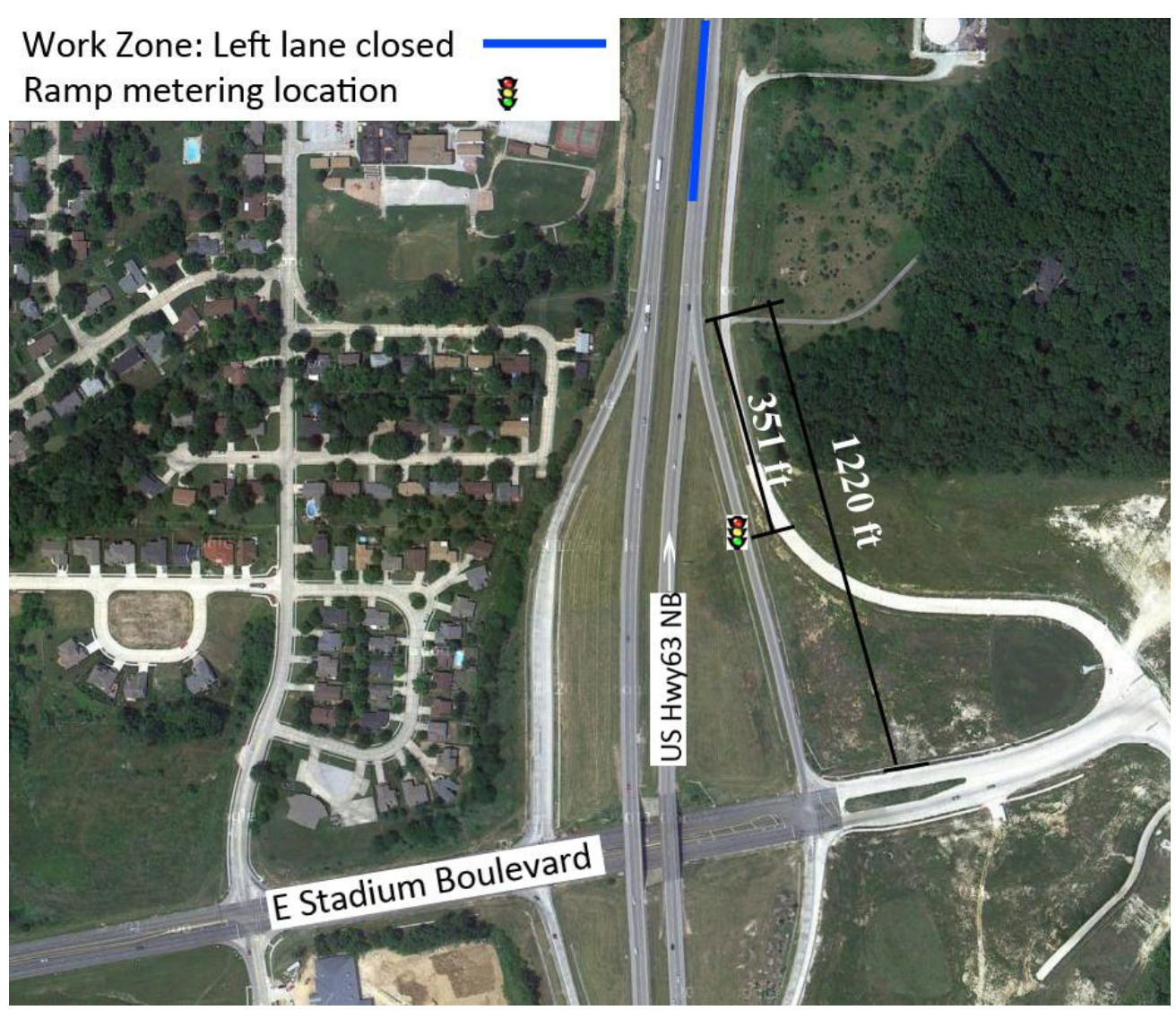

Figure 2.13 Work zone layout on US 63 NB at Stadium, left lane closed. 


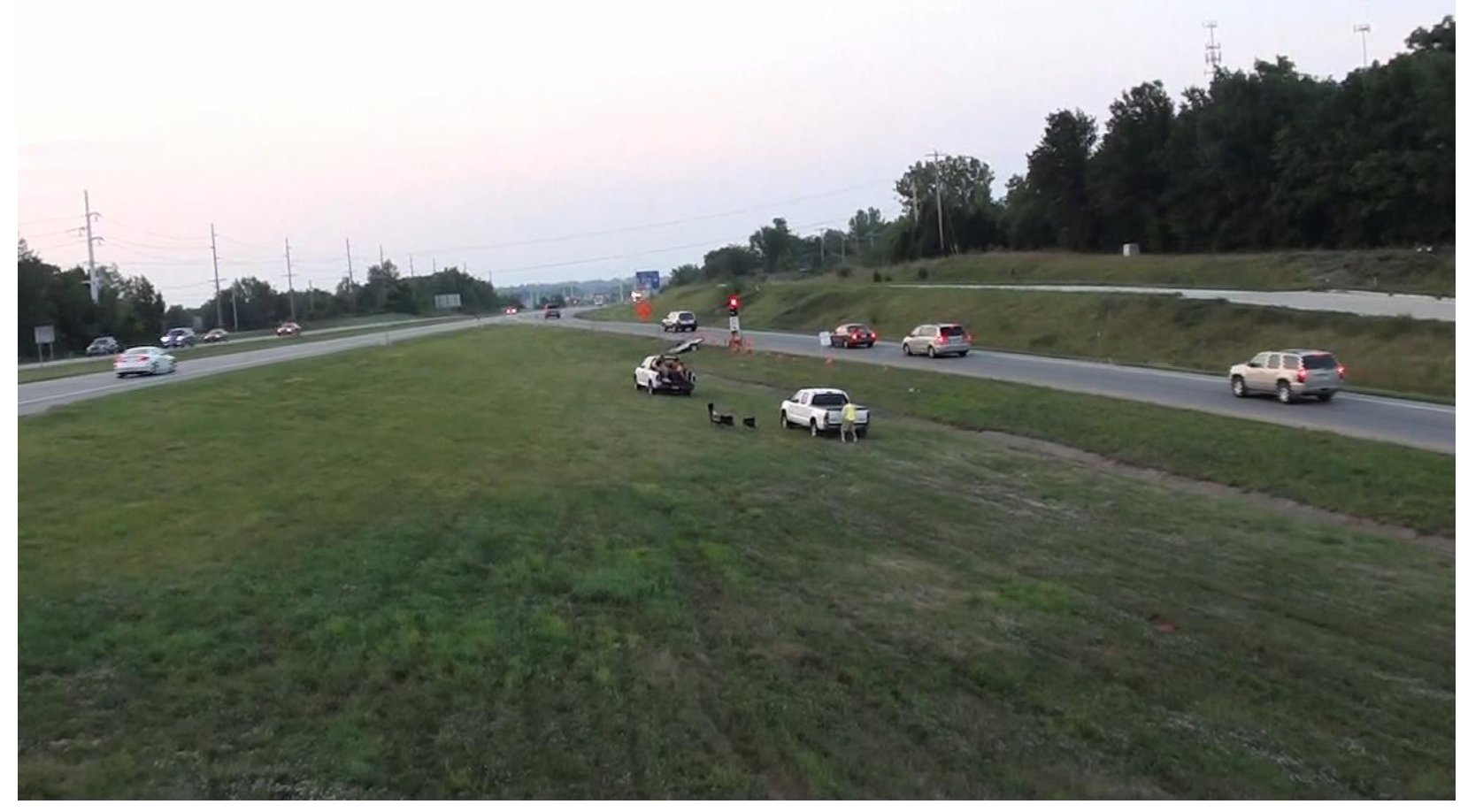

Figure 2.14 US-63 NB at Stadium.

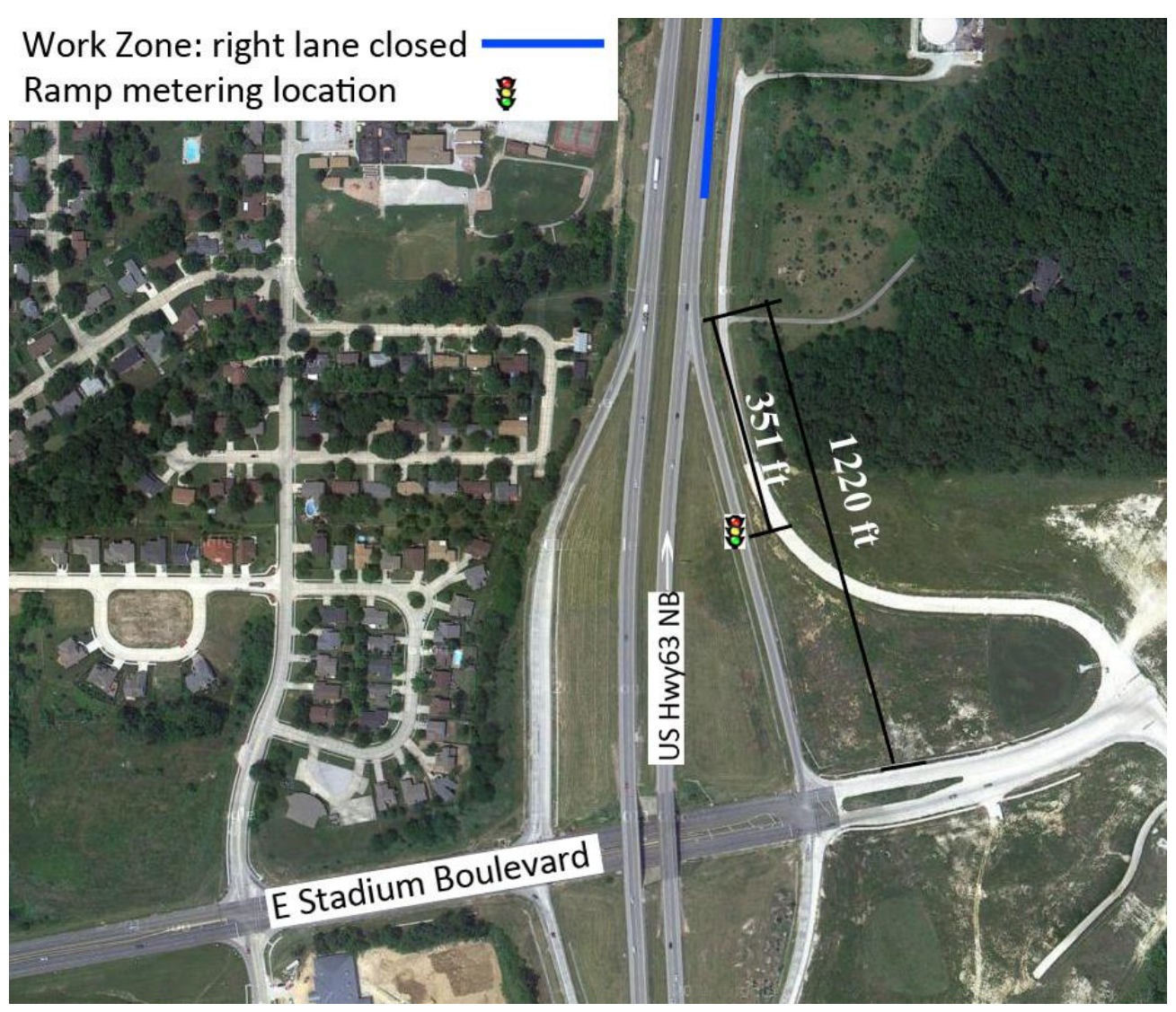

Figure 2.15 Work zone layout on US-63 at Stadium, right lane closed. 


\section{MEHTHODOLOGY}

\subsection{Safety Analysis}

Since the research objectives involved the investigation of both the safety and the mobility aspects of temporary ramp metering, several performance measures were employed. Relevant statistical tests were used to assess the validity of results. In terms of safety, since temporary ramp meters are deployed for a short period of time, an adequate sample size of crash data could not be collected. Thus, surrogate measures for safety were employed. These measures include driver compliance rates, speed statistics of the mainline and ramp traffic, speed differences between merging vehicles and mainline vehicles, ramp platoons, and merging headways.. In terms of mobility, there was only limited access to congested field sites, because the Missouri Department of Transportation (MoDOT) shifted to night work at congested locations. Despite the fact that all work zones were located in an urban area within metropolitan Columbia, work zones were delayed until after the evening peak had subsided. Thus fieldcalibrated microscopic simulation was used for investigating mobility effects. Simulation also had the added capability of performing sensitivity and scenario analysis. All simulation models were calibrated extensively using field data.

A total of four cameras were deployed at each work zone along with two speed radars. A camera on a twenty-foot tripod captured the entire ramp location including both the mainline and the ramp. This was a zoomed-out field-of-view. A zoomed-in field-of-view was recorded in order to have a clearer view of the merging interactions. Figure 3.1 shows the view of the zoomed-out camera with an inserted picture from the zoomed-in camera.

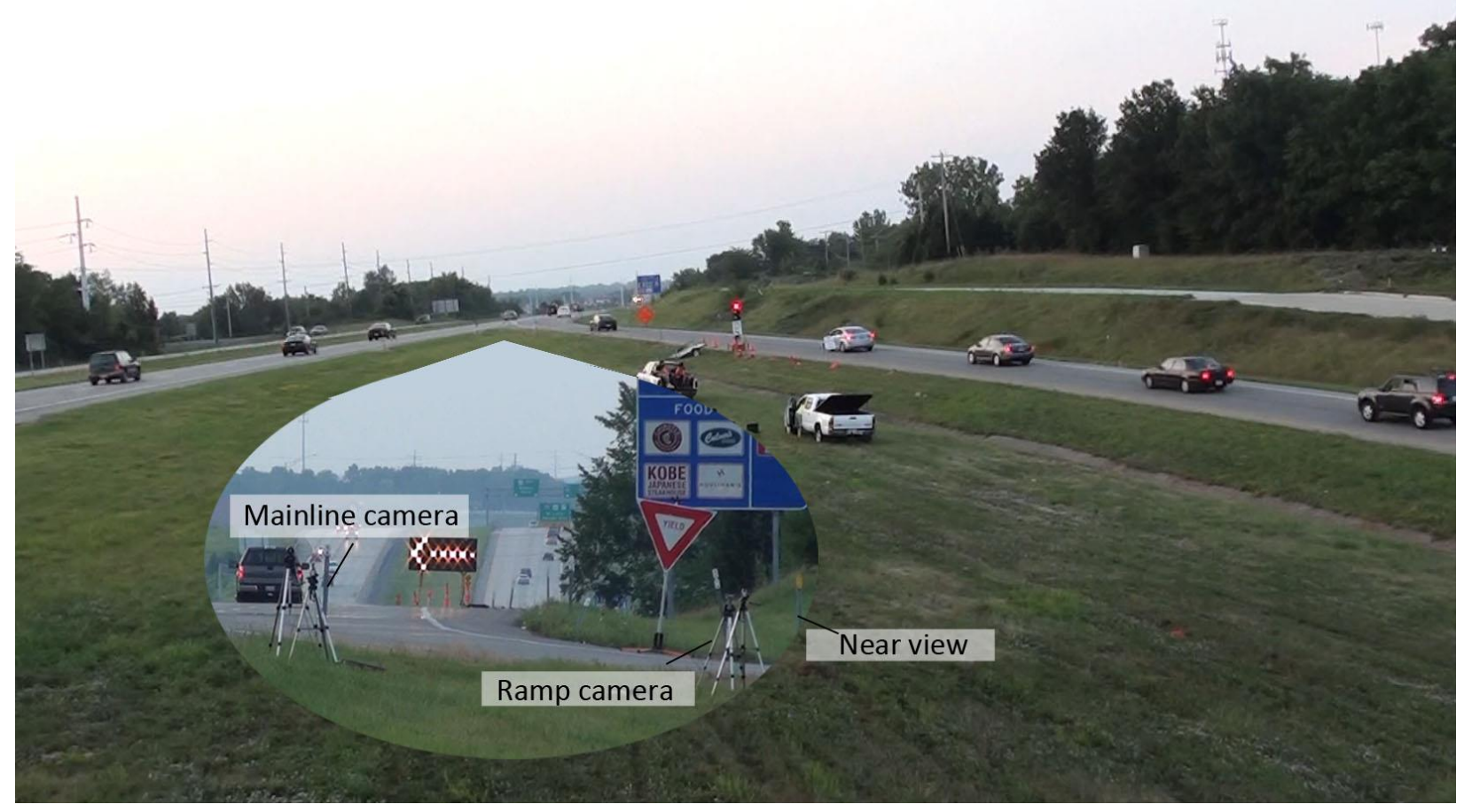

Figure 3.1 Radar gun and camera set up.

A camera was paired with a speed radar gun for monitoring the mainline and the ramp as shown in Figure 3.2. Those familiar with radar operation know that radars need to be deployed 
with skill as unintended vehicles could be picked up such as opposing vehicles. All the cameras were time-synchronized to one another.

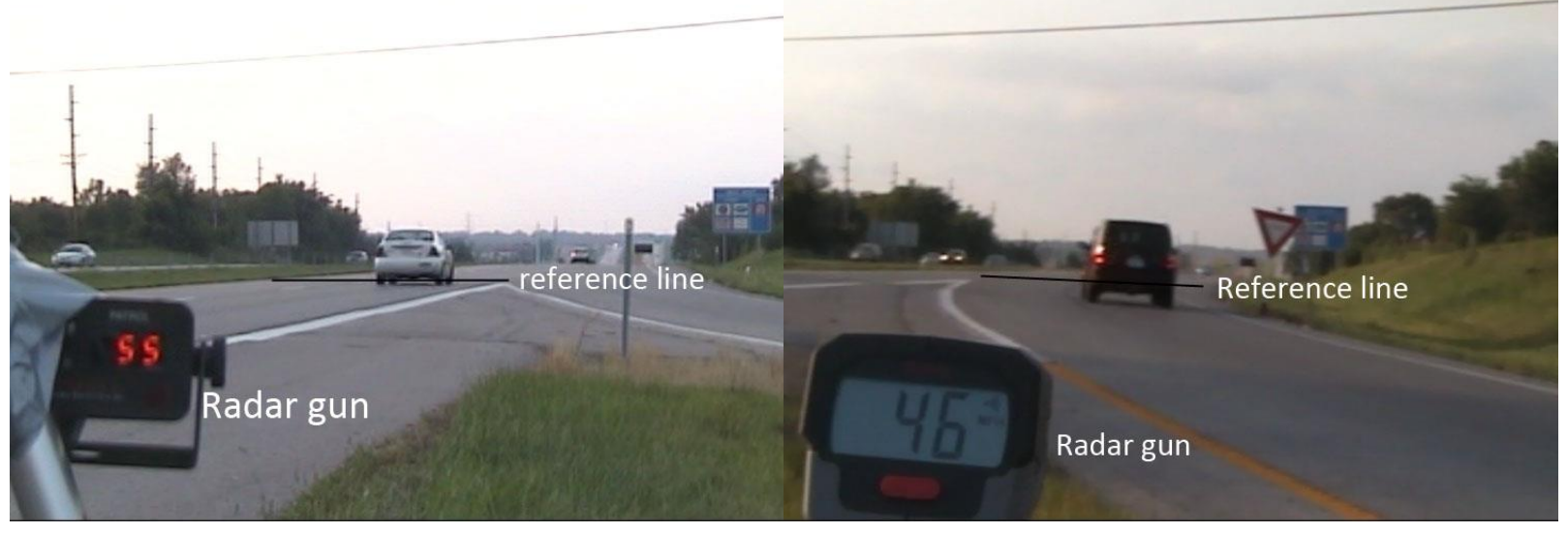

Figure 3.2 Mainline camera vision (left) and Ramp camera vision (right).

For compliance analysis, videos of ramp vehicle behavior were captured at each work zone and processed visually. A vehicle is said to have complied with the ramp meter if it went through the signal when the signal display is green. The vehicle class was recorded so that passenger and commercial vehicles could be studied independently. If more than one vehicle arrived at the meter, the number of platoon vehicles was noted.

The gore point was used as the common reference point for determining speeds in videos. Three variables were extracted from the mainline video: time when the front end of a vehicle reached the reference line, mainline speed, and vehicle type. Four variables were extracted from the ramp video: time when the front end of a vehicle reached the reference line, speed of the ramp vehicle, vehicle type, and whether the vehicle was in a platoon. Student's t-test was used to test the statistical significance of the difference between mean speeds with and without ramp metering (11). Similarly, F-test was used to test the difference in standard deviations (11). Both the mainline speeds and ramp speeds were analyzed.

In studying the interactions between a merging vehicle and mainline vehicles, the concept of a platoon-forming threshold was used. This threshold was derived from the Highway Capacity Manual (12) level of service (LOS) criteria for merge and diverge events on freeways. According to HCM, LOS A represents unrestricted merge and diverge conditions. Drivers start to be influenced by merging and diverging maneuvers at LOS B. The critical point between LOS A and $\mathrm{B}$ is a density of $10 \mathrm{pc} / \mathrm{mi} / \mathrm{ln}$, which is equivalent to $600 \mathrm{pc} / \mathrm{hr}$ or an average headway of 6 seconds at the speed of $96.5 \mathrm{kph}(60 \mathrm{mph})$. Therefore, the platoon-forming threshold was set to 6 seconds, meaning that any headway longer than this factor was not relevant to the analysis of merging vehicles. A headway shorter than this factor might result in a merging vehicle causing turbulence on the mainline, resulting in lane-changes or braking maneuvers. The 6-second time headway between the leading and merging vehicle and the merging and trailing vehicle results in a maximum time headway of 12 seconds when leading and trailing were both present. If a platoon was attempting a merge than this the threshold is increased by 6 seconds for each additional vehicle beyond a single merging vehicle.

The speed difference between a merging vehicle and mainline vehicle(s) was extracted for each merging event with and without ramp meter. The relevant mainline vehicle is a vehicle 
that traveled in the right lane and located either in front or behind the merging vehicle within the platoon-forming factor. After extracting individual speeds from video, the mainline vehicles and the merging ramp vehicle were synchronized based on the time they crossed the gore point. The speed differences with and without ramp metering were compared statistically using the aforementioned t-test and the KS distribution test (11). The expectation was that vehicles released from ramp meters have a shorter distance to accelerate, resulting in larger speed differences.

Another safety measure extracted from video was headways accepted by merging vehicles. Longer headways on the mainline provide the driver with more time to react and merge safely. For every merge event, the time headway on the mainline was extracted by computing the difference between the time when the leading vehicle or the trailing vehicle crossed the gore point. The gore point was used, since the exact location of the merge was not easily identifiable.

\subsection{Mobility Analysis}

The traffic demand observed on mainline and ramps at the seven work zones studied in the report was not continuously high for the ramp meter to have a sustained effect on mobility. Therefore, traffic simulation was used to investigate the mobility effects of ramp metering for work zones. A simulation model of a two-to-one lane work zone was created in the VISSIM microscopic simulation software. In order to use simulation for work zone mobility analysis, there has to be adequate calibration of the driving behavior parameters to reflect driving population and vehicle characteristics. The models were calibrated using field data collected at a congested work zone site in Columbia, Missouri. The initial calibration was performed using data from a previous study (13). For the current study, video was processed to obtain "following time headways" of vehicles. Radar speed gun measurements provided vehicle speeds. The VISSIM car-following model known as the Wiedemann 99 model assumes that a vehicle must maintain a minimum desired following distance at all times. Since the minimum following distances are critical only under congested conditions, only time headways of less than 3 seconds were considered for calibration. In contrast, the following distances and time headways are longer during free flow conditions.

The minimum desired following distance, $\mathrm{ABX}$, is expressed as:

$$
\mathrm{ABX}-\mathrm{L}_{\mathrm{n}-1}-\mathrm{CC} 0=\mathrm{CC} 1 * \mathrm{v}_{\text {follower }}
$$

where:

$L_{n-1}$ is the length of leading vehicle,

CCO is desired rear bumper-to-front bumper distance between stopped cars, $v_{\text {follower }}$ is speed of the following vehicle

The CC0 parameter, named the standstill distance, was kept at the default value of 4.92 feet since it was mainly applicable for stopped conditions and for simplicity of the calibration process. By keeping $\mathrm{CC} 0$ constant, the $\mathrm{CC} 1$ parameter was estimated using linear regression. Typical vehicle lengths were obtained from AASHTO Green Book (10) as 19 feet for passenger cars, 55.5 feet for Intermediate Semitrailer WB-50, 68.5 feet for WB-62 and 73.5 feet for long trucks and double-semitrailers. The left hand side of equation (1) was then calculated and used as dependent variable in linear regression while speed of the following vehicle was the independent variable. As is evident the regression line will pass through the origin, and the slope is the CC1 
value. The calibration process produced a $\mathrm{CC} 1$ value of 2.06 seconds. The simulation model with the updated $\mathrm{CC} 1$ parameter value was then validated by comparing the work zone capacity produced by the model with actual capacity value observed at the site. The calibrated model produced a capacity value of $1317 \mathrm{pcphpl}$ that is similar to the observed field capacity value of 1356 pcphpl (3\% higher) on one day. The field capacity was 19\% higher on another day (1564 pcphpl).

The mobility impact of ramp metering was measured in terms of total vehicular delay. The total delay consisted of both the mainline and ramp vehicles. Three traffic volume levels and two truck percentage levels were studied using simulation. The capacity value of a two-to-one lane work zone used by Missouri DOT was $1240 \mathrm{veh} / \mathrm{hr}$. One traffic level captured the under capacity conditions $(900 \mathrm{veh} / \mathrm{hr}=650 \mathrm{veh} / \mathrm{hr}$ mainline plus $250 \mathrm{veh} / \mathrm{hr} \mathrm{ramp})$, one captured capacity conditions $(1240 \mathrm{veh} / \mathrm{hr}=900 \mathrm{veh} / \mathrm{hr}$ mainline plus $340 \mathrm{veh} / \mathrm{hr} \mathrm{ramp})$, and one above capacity conditions $(1754 \mathrm{veh} / \mathrm{hr}=1240 \mathrm{veh} / \mathrm{hr}$ mainline plus $514 \mathrm{veh} / \mathrm{hr} \mathrm{ramp})$. A low truck percentage of $10 \%$ and high truck percentage of $40 \%$ were studied. These two truck percentages reflect typical urban and rural truck percentages in Missouri. Simulation models were developed for three work zones on I-70 and two work zones on US 63 for these six traffic level combinations. Models were created for metered ramp and unmetered ramp conditions. The delays experienced by mainline and ramp vehicles were obtained from the simulation. The percentage change in total delay was computed as the 'total delay with metering' minus the 'total delay without metering' divided by the 'total delay with metering'. 


\section{RESULTS}

\subsection{Driver Compliance Rate}

The preliminary issue investigated for the compliance study was to find a signalization scheme that would work well for work zones in Columbia. The FHWA Ramp Management and Control Handbook (9) recommends a minimum cycle time of 4 seconds, composed of 2.5 seconds of red plus 1.5 seconds of green. This results in a discharge rate of 900 vehicles/hour. The lowest practical discharge rate is 240 vehicles/hour from a 15-second cycle time. The MUTCD section on the design of freeway entrance ramp control signals (8) allows the use of both two-section and three-section heads, thus both configurations were investigated. After some preliminary calculations of the required discharge rate based on observed ramp flows, the following four signalization schemes were developed:

- 2-section head: 4 seconds red, 2 seconds green, 6 seconds cycle (4R-2G)

- 2-section head: 4 seconds red, 3 seconds green, 7 seconds cycle (4R-3G)

- 3-section head: 4 seconds red, 1 second amber, 3 seconds green, 8 seconds cycle (4R-1Y$3 \mathrm{G})$

- 3-section head: 4 seconds red, 1 second amber, 2 seconds green, 7 seconds cycle (4R-1Y2G)

Assuming that only one vehicle is released per cycle, the discharge rates ranged from 450 vehicles/hour to 600 vehicles/hour. All four configurations were deployed on the same ramp at I70 and St. Charles Road. The following sample sizes and compliance rates were obtained for the configurations:

- 4R-2G: $\mathrm{N}=37,45.5 \%$ compliance

- 4R-3G: $\mathrm{N}=50,54.0 \%$ compliance

- 4R-1Y-2G: $\mathrm{N}=112,75.0 \%$ compliance

- 4R-1Y-3G: $\mathrm{N}=92,69.6 \%$ compliance

A much higher compliance rate resulted when a three-section signal head was used. Field observations of driver behavior supported the statistical disparity between two and three-section head operation. Some drivers simply did not know what to do while facing a temporary twosection head. One possible reason for this disparity could be that drivers were not familiar with permanent ramp meters, but were familiar with the typical three-section signal head. In Missouri, permanent ramp meters with two-section heads have only been deployed in the Kansas City area which is approximately 120 miles away from Columbia. The $4 \mathrm{R}-1 \mathrm{Y}-2 \mathrm{G}$ scheme had the highest compliance rate. Field observations revealed that 3 seconds green time was too long, since it sometimes resulted in multiple vehicles released during a single cycle. The statistical significance of the compliance rates among the different signalization schemes was investigated using paired z-tests. According to the comparison results in table 4.1, all comparisons had low pvalues, thus were statistically significant except for the comparison between $4 \mathrm{R}-1 \mathrm{Y}-2 \mathrm{G}$ and $4 \mathrm{R}-$ $1 \mathrm{Y}-3 \mathrm{G}(\mathrm{p}$-value $=0.20)$. Because $4 \mathrm{R}-1 \mathrm{Y}-2 \mathrm{G}$ had the highest statistical compliance rate, it was used for all subsequent deployments. 
Table 4.1 Hypothesis Test for Compliance Rates

\begin{tabular}{|c|c|}
\hline & p-value \\
\hline 4R-2G vs 4R-3G & 0.10 \\
\hline 4R-2G vs 4R-1Y-2G & 0.00 \\
\hline 4R-2G vs 4R-1Y-3G & 0.00 \\
\hline 4R-3G vs 4R-1Y-2G & 0.00 \\
\hline 4R-3G vs 4R-1Y-3G & 0.03 \\
\hline 4R-1Y-2G vs 4R-1Y-3G & 0.20 \\
\hline
\end{tabular}

The 4R-1Y-2G signal scheme was deployed at six work zones in total, and the effects of ramp platoons, commercial vehicles and mainline congestion were investigated. Field observations revealed that when there were platoons on the ramps as opposed to individual vehicles, the compliance rate increased. The reason was that once the leading vehicle of a platoon complied with the ramp meter, then all subsequent vehicles also complied. A platoon is defined as two or more vehicles in proximity on a ramp. For analyzing the effect of platoons, data from Work Zones 2, 3, 6 and 7 were used. These work zones all had a similar commercial vehicle percentage of $3 \%$ or lower and low mainline volumes. As shown in Table 4.2, the average compliance rates were higher when there were ramp platoons. The $22 \%$ higher compliance rate was statistically significant $(\mathrm{p}$-value $=0.00)$.

Table 4.2 Compliance Comparison of Platoon Condition vs. Free Flow Condition

\begin{tabular}{|c|c|c|c|c|c|c|}
\hline $\begin{array}{l}\text { Work } \\
\text { zone }\end{array}$ & $\begin{array}{l}\text { Compliance } \\
\text { rate }\end{array}$ & $\begin{array}{c}\text { Ramp } \\
\text { Volume }\end{array}$ & $\begin{array}{l}\text { Compliance } \\
\text { rate }\end{array}$ & $\begin{array}{c}\text { Ramp } \\
\text { Volume }\end{array}$ & \multirow{2}{*}{$\begin{array}{c}\text { Compliance } \\
\text { rate } \\
\text { difference }\end{array}$} & \multirow{2}{*}{$\mathrm{p}$-value } \\
\hline & \multicolumn{2}{|c|}{ Platoon condition } & \multicolumn{2}{|c|}{ Free Flow Condition } & & \\
\hline WZ 2 & $85.7 \%$ & 42 & $68.6 \%$ & 70 & $17.1 \%$ & 0.01 \\
\hline WZ 3 & $76.9 \%$ & 39 & $46.6 \%$ & 88 & $30.3 \%$ & 0.00 \\
\hline WZ 6 & $87.5 \%$ & 48 & $67.8 \%$ & 59 & $19.7 \%$ & 0.01 \\
\hline WZ 7 & $91.1 \%$ & 45 & $77.3 \%$ & 66 & $13.8 \%$ & 0.02 \\
\hline Average & $85.6 \%$ & 174 & $63.6 \%$ & 283 & $22.0 \%$ & 0.00 \\
\hline
\end{tabular}

In this study, commercial vehicles were defined as vehicles other than FHWA Classes 1 and 2, which are motorcycles and passenger cars with one or two-axle trailers including light pickups and minivans. Thus, the commercial vehicle category includes buses, single unit trucks, and semi- and full tractor-trailers. A good description of the FHWA vehicle classification scheme along with graphical illustrations can be found in Pickett (14). In Table 4.3, Row A presents the compliance rates for passenger cars and commercial vehicles at work zones 5, 6, and 7 that had commercial vehicle traffic on the ramp. The compliance rate for passenger cars was slightly higher (by 3.3\%) than the compliance rate for commercial vehicles. The difference, however, was not statistically significant. The unrealized expectation was that the compliance rate would be higher for commercial vehicles, since commercial drivers are better trained and highly regulated. One reason for the counter-intuitive result was that semi-trailers had difficulty accelerating through the ramp metering within the 2-second green interval. Thus the noncompliance of commercial vehicles were different in nature than passenger vehicles. 
Table 4.3 Commercial Vehicles, Congestion and WZ Type on Compliance

\begin{tabular}{|c|c|c|c|c|c|c|}
\hline Row & $\begin{array}{l}\text { Compliance } \\
\text { rate }\end{array}$ & $\begin{array}{l}\text { Ramp } \\
\text { Volume }\end{array}$ & $\begin{array}{l}\text { Compliance } \\
\text { rate }\end{array}$ & $\begin{array}{l}\text { Ramp } \\
\text { Volume }\end{array}$ & Difference & P-value \\
\hline & \multicolumn{2}{|c|}{ Passenger Car } & \multicolumn{2}{|c|}{ Commercial Vehicles } & & \\
\hline A & $79.8 \%$ & 361 & $76.5 \%$ & 17 & $-3.3 \%$ & 0.377 \\
\hline & \multicolumn{2}{|c|}{$\begin{array}{l}\text { No Commercial } \\
\text { Vehicles }\end{array}$} & \multicolumn{2}{|c|}{$\begin{array}{l}\text { With Commercial } \\
\text { Vehicles }\end{array}$} & & \\
\hline \multirow[t]{2}{*}{ B } & $65.3 \%$ & 294 & $79.5 \%$ & 378 & $14.2 \%$ & 0.000 \\
\hline & \multicolumn{2}{|c|}{ Congested } & \multicolumn{2}{|c|}{ Near Free Flow } & & \\
\hline $\mathrm{C}$ & $67.3 \%$ & 55 & $73.8 \%$ & 619 & $6.5 \%$ & 0.161 \\
\hline & \multicolumn{2}{|c|}{ Left lane closure } & \multicolumn{2}{|c|}{ Right lane closure } & & \\
\hline $\mathrm{D}$ & $76.6 \%$ & 107 & $72.7 \%$ & 567 & $-4.0 \%$ & 0.189 \\
\hline
\end{tabular}

By examining commercial and passenger vehicles separately, the effects of commercial vehicles on other vehicles on the ramp was possibly neglected, i.e. interaction effects. Thus the data was divided into ramps that had no commercial vehicles and ramps that had commercial vehicle traffic. Row B from Table 4.3 shows the data from Work Zones 2, 3 and 4 where there were no commercial ramp vehicles and from Work Zones 4, 6 and 7 where there were commercial ramp vehicles. This data shows the compliance rate was higher by $14.2 \%$ when there were commercial vehicles on ramps. The result was statistically significant at a p-value of 0.000 .

Row $\mathrm{C}$ from Table 4.3 shows the influence of mainline congestion on ramp compliance. Work Zone 4 was highly congested as mainline speeds slowed to under $30 \mathrm{mph}$ and the level of service was F. Work Zones 2, 3, 5, 6 and 7 were free flowing. Intuitively, it is unclear why mainline congestion might affect ramp compliance behavior. However, the results in Row $\mathrm{C}$ of Table 4.3 show a lower compliance rate of $6.5 \%$ when congestion was present. The p-value of 0.161 suggests that the difference in compliance rate could be statistically significant, although not at a 5\% significance level.

When comparing different work zone types, work zones 2, 3, 4, 5 and 7 were combined together to obtain a large sample of left lane closures, and Work Zone 6 was the only one with a right lane closure. The results in Row D indicate slightly higher compliance rate when the left lane is closed though the difference is too small to be statistically significant.

The last investigation of compliance was concerning the effects of work zone-ramp configuration. As shown in Table 4.4, the compliance rate was lowest when the entrance ramp was before a work zone and highest when the ramp was between work zones. Hypothesis test results shown in Table 4.5 further confirm that the $-8.5 \%$ difference between these lowest and highest compliance rates was statistically significant. The compliance rates between 'before versus after', and 'between versus after' were not statistically different. 
Table 4.4 WZ-Ramp Configurations on Compliance

\begin{tabular}{|c|c|}
\hline Compliance rate & Ramp Volume \\
\hline \multicolumn{2}{|c|}{ Before work zone } \\
\hline $70.5 \%$ & 400 \\
\hline \multicolumn{2}{|c|}{ Between work zones } \\
\hline $79.0 \%$ & 162 \\
\hline \multicolumn{2}{|c|}{ After work zones } \\
\hline $75.0 \%$ & 112 \\
\hline
\end{tabular}

Table 4.5 Hypothesis Testing for Compliance across Configurations

\begin{tabular}{|c|c|}
\hline Difference & p-value \\
\hline \multicolumn{2}{|c|}{ Before vs. Between } \\
\hline$-8.5 \%$ & 0.015 \\
\hline \multicolumn{2}{|c|}{ Before vs. After } \\
\hline$-4.5 \%$ & 0.168 \\
\hline \multicolumn{2}{|c|}{ Between vs. After } \\
\hline $4.0 \%$ & 0.220 \\
\hline
\end{tabular}

In summary the compliance analysis shows that lack of compliance could be a significant issue in the deployment of temporary ramp meters. Compliance is lower under free flow ramp conditions $(63.6 \%)$ which might mean that ramp meters should be turned off under low ramp volumes. Congested mainline conditions resulted in a slightly lower compliance rate, but that result might not be statistically significant. The presence of commercial vehicles on ramps helped to increase compliance rates, thus such presence is not a problem in the deployment of temporary ramp meters. Left lane closure might have a positive effect on compliance though it is not statistically shown. Compliance rate was the highest for locations where the metered ramp is between two work zones and lowest for locations where the metered ramp was upstream of the work zone. But it is unclear if the work zone-ramp configuration results suggest a particular strategy with respect to ramp metering implementation.

\subsection{Effect of Temporary Ramp Meter on Speed}

\subsubsection{Overall Trend Analysis:}

Two sets of speed-based performance measures were used to assess the performance of temporary ramp meters. One set of measures included the mean, median and standard deviation of the mainline and the ramp vehicle speeds. Another is the speed differential between a merging vehicle and mainline vehicles that are close to the merging vehicle. Four out of seven work zones produced usable vehicle speeds on both the mainline and the ramp. Some of the work zones had geometric configurations such as horizontal and vertical curves that caused problems for the radar guns. The four work zones shared many similar characteristics such as a two-to-one lane drop, $60 \mathrm{mph}$ speed limit, the similar driver population, the same time-of-day and similar flow rates. Thus the data from these work zones were combined together. At each work zone, speeds were collected for both with and without ramp meter conditions. Table 4.6 shows the summary of the speed-related performance measures. 
Table 4.6 Speed Measures for Mainline and Ramp

\begin{tabular}{|c|c|c|c|c|c|}
\hline & Sample Size & Mean, mph & Std. Dev., mph & $\begin{array}{l}\text { Means, } \\
\text { p-value }\end{array}$ & $\begin{array}{l}\text { Variance, } \\
\text { p-value }\end{array}$ \\
\hline \multicolumn{6}{|c|}{ Mainline Speed at Merge Point } \\
\hline $\begin{array}{c}\text { Ramp } \\
\text { Meter Off }\end{array}$ & 293 & 57.26 & 6.25 & \multirow{2}{*}{0.01} & \multirow{2}{*}{0.00} \\
\hline $\begin{array}{c}\text { Ramp } \\
\text { Meter On }\end{array}$ & 356 & 55.78 & 8.09 & & \\
\hline \multicolumn{6}{|c|}{ Ramp Speed at Merge Point } \\
\hline $\begin{array}{c}\text { Ramp } \\
\text { Meter Off }\end{array}$ & 385 & 46.88 & 5.95 & \multirow{2}{*}{0.00} & \multirow{2}{*}{0.07} \\
\hline $\begin{array}{c}\text { Ramp } \\
\text { Meter On }\end{array}$ & 409 & 37.74 & 5.26 & & \\
\hline \multicolumn{6}{|c|}{ Speed Differentials } \\
\hline & $\begin{array}{l}\text { Sample Size } \\
\text { Lead/Follow }\end{array}$ & $\begin{array}{c}\text { Lead, Mean, } \\
\text { mph }\end{array}$ & $\begin{array}{c}\text { Follow, Mean, } \\
\text { mph }\end{array}$ & $\begin{array}{l}\text { Lead } \\
\text { Means, } \\
\text { p-value }\end{array}$ & $\begin{array}{l}\text { Follow } \\
\text { Means, } \\
\text { p-value }\end{array}$ \\
\hline $\begin{array}{c}\text { Ramp } \\
\text { Meter Off }\end{array}$ & $164 / 153$ & -10.34 & -9.78 & \multirow{2}{*}{0.00} & \multirow{2}{*}{0.00} \\
\hline $\begin{array}{c}\text { Ramp } \\
\text { Meter On }\end{array}$ & $185 / 149$ & -19.39 & -19.43 & & \\
\hline
\end{tabular}

For the mainline, the mean speed decreased slightly by $2.58 \%$ with ramp operation, but the standard deviation greatly increased by $29 \%$. For ramp speeds, the mean speed decreased by $19.5 \%$ with ramp operation, and the standard deviation decreased by $11.6 \%$. It appears that the decrease in ramp speeds caused an increase in the standard deviation in mainline speeds. The changes in mean speed and standard deviation of speed for both mainline and ramp were statistically significant as shown by the p-values for the t- and F-tests.

In addition to aggregate measures such as mean speed and standard deviation, the microscopic measure of the speed differential between a merging ramp vehicle and the mainline vehicle(s) in its vicinity was also analyzed. The speed differential between a merging vehicle and the leading vehicle on the mainline and the speed differential between a merging vehicle and the trailing vehicle on the mainline are shown in Table 4.6. Both speed differentials were significantly higher when the ramp meter was on. Leading speed differences increased by $87.52 \%$ and trailing speed differentials increased by $98.67 \%$. These increases were statistically significant. Increases in speed differentials result in a decrease in safety. This could be a result of the existing ramp length and acceleration lane length at the study sites. Longer ramp and acceleration lane lengths will produce smaller speed differentials since ramp vehicles will have longer distances to reach highway speeds.

\subsubsection{Analysis for Different Classification Groups:}

The data collected at all sites were classified in two different ways in order to gain insights into the effect of work zone-ramp configuration and left versus right lane closure. One way, Classification I, was to group data based on ramp location in relation to the work zone. Group 1 consisted of sites with entrance ramp before (i.e., upstream) the work zone, and Group 2 
consisted of sites with entrance ramp in between two work zones. The second way, Classification II, involved separating data based on the position of lane closure. Group 1 consisted of sites with a right lane closure, and Group 2 consisted of sites with a left lane closure.

Classification I: Effect of ramp metering on mainline speed

Speed measures for mainline vehicles for the two groups in Classification I are shown in Table 4.7. For both groups in Classification I, mean speed decreased and standard deviation increased when ramp meter was turned on. The small p-values indicate that the changes were statistically significant. The results of the comparison between the two groups in Classification I with ramp metering are shown in Table 4.8 and without metering in Table 4.9. For both conditions, meter on and off, the mean speed for 'ramp between work zones' group was slightly greater than the mean speed for 'ramp before work zone' group. Thus, in the 'ramp between work zones' group, vehicles on the mainline appeared to have accelerated after leaving the first work zone and thus reached higher speeds than mainline vehicles in the 'ramp before work zone' group. The difference in the mean speeds between the two groups was $2.54 \mathrm{mph}$ with meter and $3.10 \mathrm{mph}$ without meter. The standard deviation of speeds was observed to be higher for the 'ramp before work zone' group. All observed differences were statistically significant.

Table 4.7 Mainline Speeds During Merging

\begin{tabular}{|c|c|c|c|c|c|}
\hline $\begin{array}{c}\text { Ramp between work } \\
\text { zones }\end{array}$ & $\begin{array}{c}\text { Flow Rate } \\
\text { (veh/hr/lane) }\end{array}$ & Mean & Median & $\begin{array}{c}\text { Standard } \\
\text { deviation }\end{array}$ & Trucks \% \\
\hline Ramp meter off & 338 & 59.52 & 59 & 4.40 & $32.16 \%$ \\
\hline Ramp meter on & 314 & 57.66 & 59 & 6.68 & $37.58 \%$ \\
\hline difference & - & 1.86 & 0 & -2.28 & $5.42 \%$ \\
\hline on vs. off, p-value & - & 0.015 & - & 0.00 & 0.140 \\
\hline \hline Ramp before work zone & $\begin{array}{c}\text { Flow Rate } \\
\text { (veh/hr/lane) }\end{array}$ & Mean & Median & $\begin{array}{c}\text { Standard } \\
\text { deviation }\end{array}$ & Trucks \% \\
\hline Ramp meter off & 391 & 56.42 & 57 & 6.79 & $11.89 \%$ \\
\hline Ramp meter on & 402 & 55.12 & 56 & 8.54 & $9.64 \%$ \\
\hline difference & - & 1.3 & 1 & -1.75 & $2.25 \%$ \\
\hline on vs. off, p-value & - & 0.03 & - & 0.00 & 0.091 \\
\hline \hline
\end{tabular}

Table 4.8 Comparing Mainline Speeds with Metering for Classification I

\begin{tabular}{|c|c|c|c|}
\hline Mainline speed & $\begin{array}{c}\text { Sample } \\
\text { size }\end{array}$ & Mean & $\begin{array}{c}\text { Standard } \\
\text { deviation }\end{array}$ \\
\hline Ramp between work zones & 93 & 57.66 & 6.68 \\
\hline Ramp before work zone & 263 & 55.12 & 8.54 \\
\hline difference & - & 2.54 & -1.86 \\
\hline p-value & - & 0.002 & 0.003 \\
\hline
\end{tabular}


Table 4.9 Comparing Mainline Speeds without Metering for Classification I

\begin{tabular}{|c|c|c|c|}
\hline Mainline speed & $\begin{array}{c}\text { Sample } \\
\text { size }\end{array}$ & Mean & $\begin{array}{c}\text { Standard } \\
\text { deviation }\end{array}$ \\
\hline Ramp between work zones & 79 & 59.52 & 4.40 \\
\hline Ramp before work zone & 214 & 56.42 & 6.79 \\
\hline difference & - & 3.10 & -2.39 \\
\hline p-value & - & 0.00 & 0.00 \\
\hline
\end{tabular}

Classification I: Effect of ramp metering on ramp speed

For both groups in classification I, the mean speed of ramp vehicles decreased when ramp meter was in operation (Table 4.10). Mean speed reductions of $10.34 \mathrm{mph}$ and $8.47 \mathrm{mph}$ were observed for 'ramp between work zones' and 'ramp before work zone' groups, respectively. The reduction in speeds was also evident in the speed distribution plots. Figure 4.1 illustrates the clear shift in speed distribution when the ramp meter was on. The differences in standard deviation of speeds with and without meter were not statistically significant for either group. The ramp speeds for each group were compared using Tables 4.11 and 4.12 for with and without ramp metering conditions. Similar to the mainline speed findings, the mean speed of ramp vehicles was higher for the 'ramp between work zones' group compared to the 'ramp before work zone' group for both with meter $(4.20 \mathrm{mph})$ and without meter $(6.13 \mathrm{mph})$ conditions.

Table 4.10 Speed of Ramp Vehicles during Merging

\begin{tabular}{|c|c|c|c|c|c|}
\hline $\begin{array}{c}\text { Ramp between work } \\
\text { zones }\end{array}$ & $\begin{array}{c}\text { Flow Rate } \\
\text { (veh/hr/lane) }\end{array}$ & Mean & Median & Standard deviation & Trucks \% \\
\hline Ramp meter off & 292 & 50.7 & 51 & 5.22 & $5.56 \%$ \\
\hline Ramp meter on & 328 & 40.3 & 40.5 & 4.93 & $8.13 \%$ \\
\hline difference & - & 10.34 & 10.5 & 0.29 & $-2.57 \%$ \\
\hline on vs. off, p-value & - & 0.00 & - & 0.481 & 0.186 \\
\hline Ramp before work zone & $\begin{array}{c}\text { Flow Rate } \\
\text { (veh/hr/lane) }\end{array}$ & Mean & Median & Standard deviation & Trucks \% \\
\hline Ramp meter off & 174 & 44.57 & 45 & 5.11 & $2.08 \%$ \\
\hline Ramp meter on & 187 & 36.10 & 36 & 5.27 & $1.62 \%$ \\
\hline difference & - & 8.47 & 9 & -0.16 & $0.46 \%$ \\
\hline on vs. off, p-value & - & 0.00 & - & 0.235 & 0.353 \\
\hline \hline
\end{tabular}




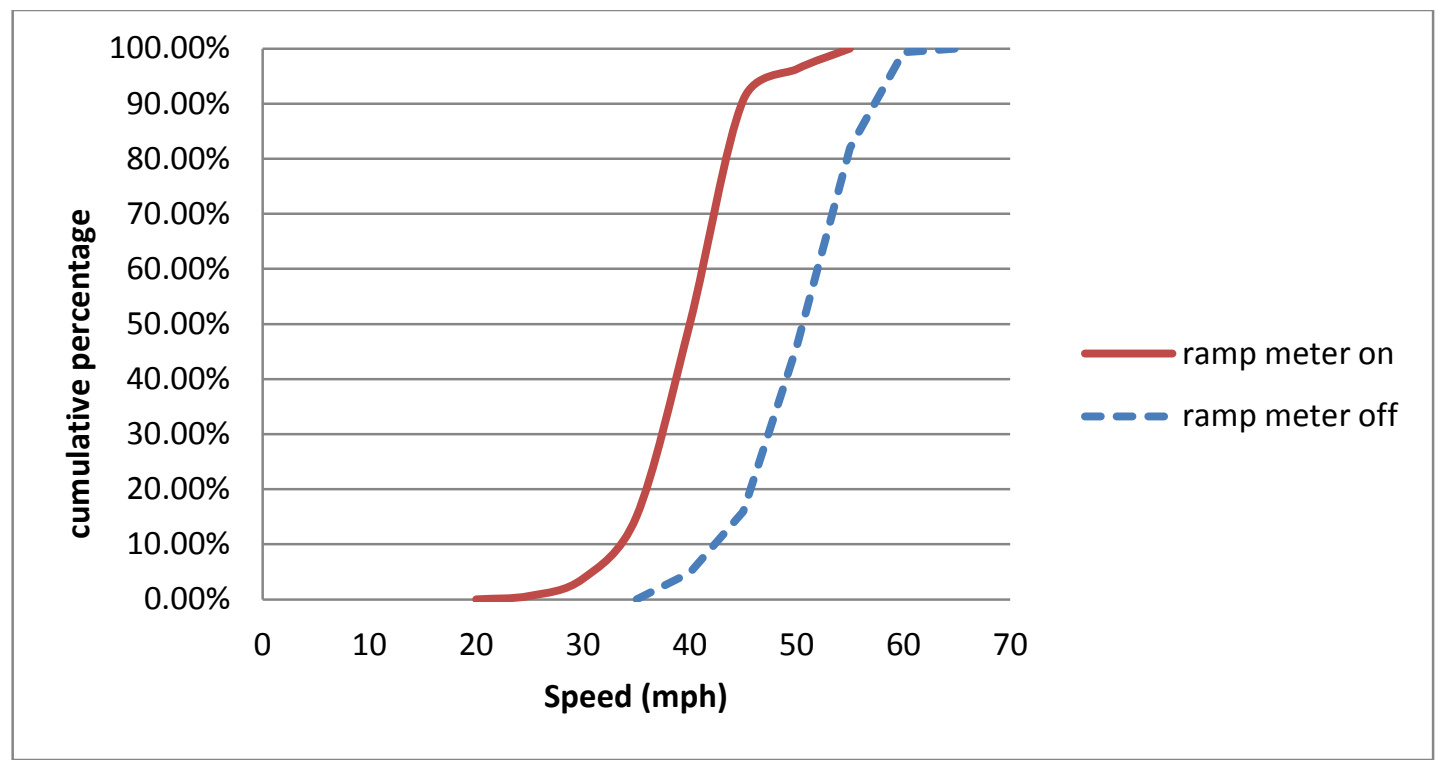

Figure 4.1 Cumulative distribution of speeds for the 'ramp between work zones' group.

Table 4.11 Comparing Ramp Speeds with Metering for Classification I

\begin{tabular}{|c|c|c|c|}
\hline Ramp speed & $\begin{array}{c}\text { Sample } \\
\text { size }\end{array}$ & Mean & $\begin{array}{c}\text { Standard } \\
\text { deviation }\end{array}$ \\
\hline Ramp between work zones & 160 & 40.30 & 4.93 \\
\hline Ramp before work zone & 248 & 36.10 & 5.27 \\
\hline difference & - & 4.20 & -0.34 \\
\hline p-value & - & 0.00 & 0.185 \\
\hline \multicolumn{2}{|r}{}
\end{tabular}

Table 4.12 Comparing Ramp Speeds without Metering for Classification I

\begin{tabular}{|c|c|c|c|}
\hline Ramp speed & $\begin{array}{c}\text { Sample } \\
\text { size }\end{array}$ & Mean & $\begin{array}{c}\text { Standard } \\
\text { deviation }\end{array}$ \\
\hline Ramp between work zones & 144 & 50.7 & 5.22 \\
\hline Ramp before work zone & 241 & 44.57 & 5.11 \\
\hline difference & - & 6.13 & 0.11 \\
\hline p-value & - & 0.00 & 0.379 \\
\hline
\end{tabular}

Classification I: Effect of ramp metering on speed differential

During merging events, the difference of speeds of the merging ramp vehicle and leading and following mainline vehicles were computed. The mean values for both groups are shown in Table 4.13. The mean speed differential increased due to ramp meter deployment in both groups. The increase was greater for the 'ramp between work zones' group (10.09 mph with leading vehicle and $11.31 \mathrm{mph}$ with following vehicle) than the 'ramp before work zone' group (8.78 mph with leading vehicle and $8.64 \mathrm{mph}$ with following vehicle). 
Table 4.13 Speed Differentials for Classification I

\begin{tabular}{|c|c|c|c|c|c|}
\hline \multirow{2}{*}{} & \multicolumn{5}{|c|}{ Speed differential } \\
\cline { 2 - 6 } & $\begin{array}{c}\text { with leading } \\
\text { vehicle }\end{array}$ & $\begin{array}{c}\text { with following } \\
\text { vehicle }\end{array}$ & Both \\
\cline { 2 - 6 } & $\begin{array}{c}\text { Mean } \\
(\mathrm{mph})\end{array}$ & count & $\begin{array}{c}\text { Mean } \\
(\mathrm{mph})\end{array}$ & count & $\begin{array}{c}\text { Mean } \\
(\mathrm{mph})\end{array}$ \\
\hline Ramp between work zones & \multicolumn{5}{|c|}{} \\
\hline ramp meter off & -8.02 & 54 & -7.77 & 57 & -7.89 \\
\hline ramp meter on & -18.11 & 74 & -19.08 & 52 & -18.51 \\
\hline Difference & 10.09 & - & 11.31 & - & 10.62 \\
\hline p-value & 0.00 & - & 0.00 & - & 0.00 \\
\hline Ramp before work zones & \multicolumn{7}{|l|}{} \\
\hline ramp meter off & -11.47 & 111 & -10.98 & 97 & -11.24 \\
\hline ramp meter on & -20.25 & 111 & -19.62 & 97 & -19.96 \\
\hline Difference & 8.78 & - & 8.64 & - & 8.72 \\
\hline p-value & 0.00 & - & 0.00 & - & 0.00 \\
\hline \hline
\end{tabular}

The mean speed differential values for both groups were compared. The results with meter deployed are shown in Table 4.14 and without meter in Table 4.15. The differences reported for leading vehicle speed differentials, of $2.14 \mathrm{mph}$ with meter and $3.45 \mathrm{mph}$ without meter, were statistically significant. Thus, with ramp metering in place the difference in mean speed differential between 'ramp between work zones' and 'ramp before work zone' groups was lower than without metering.

Table 4.14 Comparing Speed Differentials with Metering for Classification I

\begin{tabular}{|c|c|c|c|c|}
\hline \multirow{2}{*}{ Ramp metering on } & \multicolumn{4}{|c|}{ Speed Differential } \\
\cline { 2 - 5 } & \multicolumn{2}{|c|}{ with leading vehicle } & \multicolumn{2}{c|}{ with following vehicle } \\
\cline { 2 - 5 } & $\begin{array}{c}\text { Mean } \\
(\mathrm{mph})\end{array}$ & $\begin{array}{c}\text { Sample } \\
\text { size }\end{array}$ & $\begin{array}{c}\text { Mean } \\
(\mathrm{mph})\end{array}$ & $\begin{array}{c}\text { Sample } \\
\text { size }\end{array}$ \\
\hline Ramp between work zones & -18.11 & 74 & -19.08 & 52 \\
\hline Ramp before work zone & -20.25 & 111 & -19.62 & 97 \\
\hline Difference & 2.14 & - & 0.53 & - \\
\hline p-value & 0.06 & - & 0.35 & - \\
\hline
\end{tabular}


Table 4.15 Comparing Speed Differentials without Metering for Classification I

\begin{tabular}{|c|c|c|c|c|}
\hline \multirow{2}{*}{ Ramp metering off } & \multicolumn{4}{|c|}{ Speed Differential } \\
\cline { 2 - 5 } & \multicolumn{2}{|c|}{ with leading vehicle } & \multicolumn{2}{c|}{ with following vehicle } \\
\cline { 2 - 5 } & $\begin{array}{c}\text { Mean } \\
(\mathrm{mph})\end{array}$ & $\begin{array}{c}\text { Sample } \\
\text { Size }\end{array}$ & $\begin{array}{c}\text { Mean } \\
(\mathrm{mph})\end{array}$ & $\begin{array}{c}\text { Sample } \\
\text { size }\end{array}$ \\
\hline Ramp between work zones & -8.02 & 54 & -7.77 & 57 \\
\hline Ramp before work zone & -11.47 & 111 & -10.98 & 97 \\
\hline Difference & 3.45 & - & 3.21 & - \\
\hline p-value & 0.00 & - & 0.00 & - \\
\hline
\end{tabular}

In summary, for both groups in Classification I, mean speed decreased and standard deviation increased when ramp meter was turned on. When an entrance ramp is located between two work zones, vehicles on the mainline tend to accelerate as they leave the first work zone and arrive at the ramp merge location with speeds slightly higher than those observed at locations where an entrance ramp is before a work zone. However, the standard deviation of the speeds for the 'ramp between work zones' group was slightly lower than that of the 'ramp before work zone' group. The addition of a ramp meter on the entrance ramp reduced speeds of entering vehicles in both groups, with 'ramp between work zones' witnessing a slightly higher drop of $10.34 \mathrm{mph}$. This was a result of the need to stop at the signal and then to accelerate to the merge point. As expected, the mean speed differential between the ramp vehicle and the mainline vehicle (leading and following) during merging increased due to the deployment of a ramp meter for both groups. The mean speed differential with leading vehicle for the 'ramp before work zone' group was 2.14 mph higher than that of the 'ramp between work zones' group. Because the differences between the two groups are small, the lower standard deviation in the mainline speeds and the lower speed differential observed in the 'ramp between work zones' group might not indicate that ramp meter may be better suited to situations when an entrance ramp is located between two work zones.

\section{Classification II: Effect of ramp metering on mainline speed}

Classification II involved separating field data based on the position of lane closure: Group 1 being sites with a right lane closure and Group 2 being sites with a left lane closure. Speed measures for mainline vehicles for the two groups in Classification II are shown in Table 4.16. The mean speed slightly decreased for the 'left lane closure' group $(<1 \mathrm{mph})$ and the 'right lane closure' group (1.44 mph) upon deploying the ramp meter. The standard deviation increased in 'left lane closure' but remained the same in 'right lane closure'. The results of comparison between the two groups with ramp metering are shown in Table 4.17 and without metering in Table 4.18. For both conditions, meter on and off, the mean speed for 'left lane closure' group was lower than the mean speed for 'right lane closure' group. The differences in the mean speeds between the two groups were similar with $(3.19 \mathrm{mph})$ or without the ramp meter $(3.84 \mathrm{mph})$ without the meter. The deployment of ramp meter resulted in a higher standard deviation for the 'left lane closure' group than the 'right lane closure' group. 
Table 4.16 Mainline Speeds during Merging for Classification II

\begin{tabular}{|c|c|c|c|c|c|}
\hline \hline Left lane closure & $\begin{array}{c}\text { Flow Rate } \\
\text { (veh/hr/lane) }\end{array}$ & Mean & Median & $\begin{array}{c}\text { Standard } \\
\text { deviation }\end{array}$ & Trucks \% \\
\hline Ramp meter off & 344 & 54.77 & 55 & 5.31 & $5.52 \%$ \\
\hline Ramp meter on & 367 & 53.98 & 55 & 9.63 & $2.94 \%$ \\
\hline difference & - & 0.79 & 0 & -4.32 & $2.58 \%$ \\
\hline on vs. off, p-value & - & 0.404 & - & 0.00 & 0.060 \\
\hline Right lane closure & $\begin{array}{c}\text { Flow Rate } \\
\text { (veh/hr/lane) }\end{array}$ & Mean & Median & $\begin{array}{c}\text { Standard } \\
\text { deviation }\end{array}$ & Trucks \% \\
\hline Ramp meter off & 387 & 58.61 & 59 & 6.51 & $22.30 \%$ \\
\hline Ramp meter on & 382 & 57.17 & 58 & 6.50 & $21.67 \%$ \\
\hline difference & - & 1.44 & 1 & 0.01 & $0.63 \%$ \\
\hline on vs. off, p-value & - & 0.015 & - & 0.49 & 0.400 \\
\hline
\end{tabular}

Table 4.17 Comparing Mainline Speeds with Metering for Classification II

\begin{tabular}{|c|c|c|c|}
\hline Mainline speed & $\begin{array}{c}\text { Sample } \\
\text { size }\end{array}$ & Mean & $\begin{array}{c}\text { Standard } \\
\text { deviation }\end{array}$ \\
\hline Left lane closure & 152 & 53.98 & 9.63 \\
\hline Right lane closure & 202 & 57.17 & 6.50 \\
\hline difference & - & -3.19 & 3.13 \\
\hline p-value & - & 0.00 & 0.00 \\
\hline
\end{tabular}

Table 4.18 Comparing Mainline Speeds without Metering for Classification II

\begin{tabular}{|c|c|c|c|}
\hline Mainline speed & $\begin{array}{c}\text { Sample } \\
\text { size }\end{array}$ & Mean & $\begin{array}{c}\text { Standard } \\
\text { deviation }\end{array}$ \\
\hline Left lane closure & 103 & 54.77 & 5.31 \\
\hline Right lane closure & 190 & 58.61 & 6.51 \\
\hline difference & - & -3.84 & -1.20 \\
\hline p-value & - & 0.00 & 0.01 \\
\hline
\end{tabular}

Classification II: Effect of ramp metering on ramp speed

For both groups in classification II, the mean speed of ramp vehicles decreased when ramp meter was in operation (Table 4.19). Mean speed reductions of $8.62 \mathrm{mph}$ and $9.35 \mathrm{mph}$ were observed for 'left lane closure' and 'right lane closure' groups, respectively. The differences in standard deviation of speeds with and without meter were not statistically significant for either group. The ramp speeds for each group were compared using Tables 4.20 and 4.21 for with and without ramp metering conditions. The mean speed and standard deviation of ramp vehicles was higher for the 'right lane closure' group compared to the 'left lane closure' group for both with and without metering. 
Table 4.19 Speed of Ramp Vehicles during Merging for Classification II

\begin{tabular}{|c|c|c|c|c|c|}
\hline Left lane closure & $\begin{array}{c}\text { Flow Rate } \\
\text { (veh/hr/lane) }\end{array}$ & Mean & Median & $\begin{array}{c}\text { Standard } \\
\text { deviation }\end{array}$ & Trucks \% \\
\hline Ramp meter off & 218 & 44.81 & 44 & 4.38 & $3.09 \%$ \\
\hline Ramp meter on & 222 & 36.19 & 36.5 & 4.61 & $2.11 \%$ \\
\hline difference & - & 8.62 & 7.5 & -0.23 & $0.98 \%$ \\
\hline on vs. off, p-value & - & 0.00 & - & 0.623 & 0.334 \\
\hline Right lane closure & $\begin{array}{c}\text { Flow Rate } \\
\text { (veh/hr/lane) }\end{array}$ & Mean & Median & Standard deviation & Trucks \% \\
\hline Ramp meter off & 201 & 47.57 & 48 & 6.25 & $3.47 \%$ \\
\hline Ramp meter on & 228 & 38.22 & 39 & 5.70 & $4.79 \%$ \\
\hline difference & - & 9.35 & 9 & 0.55 & $-1.32 \%$ \\
\hline on vs. off, p-value & - & 0.00 & - & 0.056 & 0.207 \\
\hline
\end{tabular}

Table 4.20 Comparing Ramp Speeds with Metering for Classification II

\begin{tabular}{|c|c|c|c|}
\hline Ramp speed & $\begin{array}{c}\text { Sample } \\
\text { size }\end{array}$ & Mean & $\begin{array}{c}\text { Standard } \\
\text { deviation }\end{array}$ \\
\hline Left lane closure & 95 & 36.19 & 4.61 \\
\hline Right lane closure & 313 & 38.22 & 5.70 \\
\hline difference & - & -2.03 & -1.09 \\
\hline p-value & - & 0.00 & 0.01 \\
\hline
\end{tabular}

Table 4.21 Comparing Ramp Speeds without Metering for Classification II

\begin{tabular}{|c|c|c|c|}
\hline Ramp speed & $\begin{array}{c}\text { Sample } \\
\text { size }\end{array}$ & Mean & $\begin{array}{c}\text { Standard } \\
\text { deviation }\end{array}$ \\
\hline Left lane closure & 97 & 44.81 & 4.38 \\
\hline Right lane closure & 288 & 47.57 & 6.25 \\
\hline difference & - & -2.76 & -1.87 \\
\hline p-value & - & 0.00 & 0.00 \\
\hline
\end{tabular}

Classification II: Effect of ramp metering on speed differential

The mean values of speed differentials for both groups are shown in Table 4.22. As expected, the mean speed differential increased due to ramp meter deployment in both groups. The increase was slightly greater for the 'right lane closure' group $(9.27 \mathrm{mph}$ with leading vehicle and $9.96 \mathrm{mph}$ with following vehicle) than the 'left lane closure' group (9.22 $\mathrm{mph}$ with leading vehicle and $8.49 \mathrm{mph}$ with following vehicle).

The mean speed differential values for both groups were compared. The results with meter deployed are shown in Table 4.23 and without meter in Table 4.24. The values shown in the tables indicate that the differences between the two groups were minor $(<2 \mathrm{mph})$ and not statistically significant. 
Table 4.22 Speed Differentials for Classification II

\begin{tabular}{|c|c|c|c|c|c|}
\hline & \multicolumn{5}{|c|}{ Speed differential } \\
\hline & \multicolumn{2}{|c|}{$\begin{array}{c}\text { with leading } \\
\text { vehicle }\end{array}$} & $\begin{array}{c}\text { with following } \\
\text { vehicle }\end{array}$ & Both \\
\cline { 2 - 6 } & $\begin{array}{c}\text { Mean } \\
(\mathrm{mph})\end{array}$ & count & $\begin{array}{c}\text { Mean } \\
(\mathrm{mph})\end{array}$ & count & $\begin{array}{c}\text { Mean } \\
(\mathrm{mph})\end{array}$ \\
\hline Left lane closure & \multicolumn{5}{|c|}{} \\
\hline ramp meter off & -9.91 & 65 & -9.03 & 58 & -9.50 \\
\hline ramp meter on & -18.40 & 62 & -18.25 & 59 & -18.32 \\
\hline Difference & 8.49 & - & 9.22 & - & 8.82 \\
\hline p-value & 0.00 & - & 0.00 & - & 0.00 \\
\hline Right lane closure & \multicolumn{7}{|l|}{} \\
\hline ramp meter off & -10.62 & 99 & -10.24 & 95 & -10.43 \\
\hline ramp meter on & -19.89 & 123 & -20.2 & 90 & -20.02 \\
\hline Difference & 9.27 & - & 9.96 & - & 9.59 \\
\hline p-value & 0.00 & - & 0.00 & - & 0.00 \\
\hline
\end{tabular}

Table 4.23 Comparing Speed Differentials with Metering for Classification II

\begin{tabular}{|c|c|c|c|c|}
\hline \multirow{2}{*}{ Ramp metering on } & \multicolumn{4}{|c|}{ Speed Differential } \\
\cline { 2 - 5 } & \multicolumn{2}{|c|}{ with leading vehicle } & \multicolumn{2}{c|}{ with following vehicle } \\
\cline { 2 - 5 } & $\begin{array}{c}\text { Mean } \\
(\mathrm{mph})\end{array}$ & $\begin{array}{c}\text { Sample } \\
\text { Size }\end{array}$ & $\begin{array}{c}\text { Mean } \\
(\mathrm{mph})\end{array}$ & $\begin{array}{c}\text { Sample } \\
\text { size }\end{array}$ \\
\hline Left lane closure & -18.40 & 62 & -18.25 & 59 \\
\hline Right lane closure & -19.89 & 123 & -20.2 & 90 \\
\hline Difference & 1.49 & - & 1.95 & - \\
\hline p-value & 0.16 & - & 0.10 & - \\
\hline
\end{tabular}

Table 4.24 Comparing Speed Differentials without Metering for Classification II

\begin{tabular}{|c|c|c|c|c|}
\hline \multirow{2}{*}{ Ramp metering off } & \multicolumn{4}{|c|}{ Speed Differential } \\
\cline { 2 - 5 } & \multicolumn{2}{|c|}{ with leading vehicle } & \multicolumn{2}{c|}{ with following vehicle } \\
\cline { 2 - 5 } & $\begin{array}{c}\text { Mean } \\
(\mathrm{mph})\end{array}$ & $\begin{array}{c}\text { Sample } \\
\text { size }\end{array}$ & $\begin{array}{c}\text { Mean } \\
(\mathrm{mph})\end{array}$ & $\begin{array}{c}\text { Sample } \\
\text { size }\end{array}$ \\
\hline Left lane closure & -9.91 & 65 & -9.03 & 58 \\
\hline Right lane closure & -10.62 & 99 & -10.24 & 95 \\
\hline Difference & 0.71 & - & 1.21 & - \\
\hline p-value & 0.28 & - & 0.15 & - \\
\hline
\end{tabular}

In summary, the mean speed of mainline vehicles slightly decreased for the 'left lane closure' group and the 'right lane closure' group upon deploying ramp meter. The standard deviation increased in 'left lane closure' but remained the same in 'right lane closure' group. The deployment of ramp meter did not have an effect on the difference in the mean speeds between the two groups but resulted in a higher standard deviation for the 'left lane closure' group than 
the 'right lane closure' group. The reduction in mean speeds of ramp vehicles with ramp metering was similar for both groups. The mean speed and standard deviation of ramp vehicles was higher for the 'right lane closure' group compared to the 'left lane closure' group for both with and without metering conditions. Finally, the difference in mean speed differential values between the two groups was found to be insignificant. These findings are not conclusive enough to recommend ramp meter for one group over the other. The lower standard deviation in the mainline speeds and the higher mean speeds of ramp vehicles make the 'right lane group' a better candidate for ramp metering. However, the 'right lane closure' group also exhibited higher standard deviations in ramp vehicle speeds than the 'left lane closure' group.

\subsection{Measures Associated with Merge Point}

Two additional measures associated with the interaction of the merging ramp vehicle with mainline vehicles were analyzed. These measures are merging headways and merging platoons. The headways accepted by merging vehicles were examined to see if there were any differences between the 'with' and 'without' ramp meter conditions. In general, a longer headway accepted by a merging vehicle is safer than a shorter headway. A slight shift in the headway distribution towards longer headways was observed due to ramp metering. For example, according to Figure 4.2, the median value of headway was 6.24 seconds with ramp meters as opposed to 5.82 seconds without ramp meters. However, the result of the K-S test comparing the two cumulative distributions was not statistically significant $(\mathrm{p}$-value $=0.417)$.

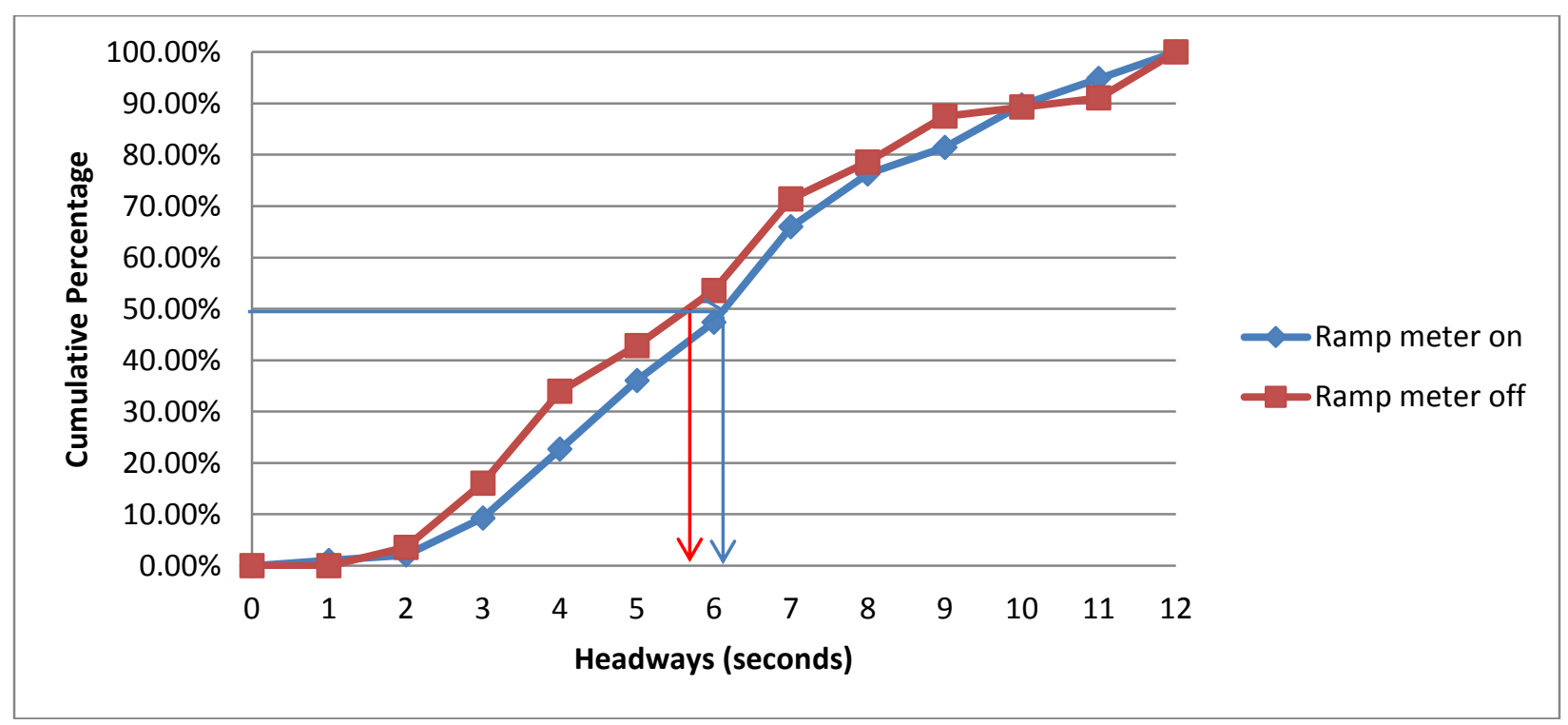

Figure 4.2 Merging headway cumulative distribution plot.

Two or more vehicles merging simultaneously is defined as a platoon merge in this study. Although there were not enough samples to do comparisons among platoon sizes, there was sufficient data to compare a single-vehicle merge versus multi-vehicle merges. Longer gaps are required for multi-vehicle merges than single-vehicle merges. One objective of ramp meters is to break up platoon merges so that merges could be safer and less disruptive to mainline traffic. Figure 4.3 shows the frequency of platoon merges for different number of vehicles. Of particular interest, is the percentage of single-vehicle merges which was over $70 \%$ for metering and less 
than $50 \%$ for without ramp metering. Correspondingly, Figure 4.3 shows that ramp metering results in fewer platoon merges. This result is desirable from a safety perspective.

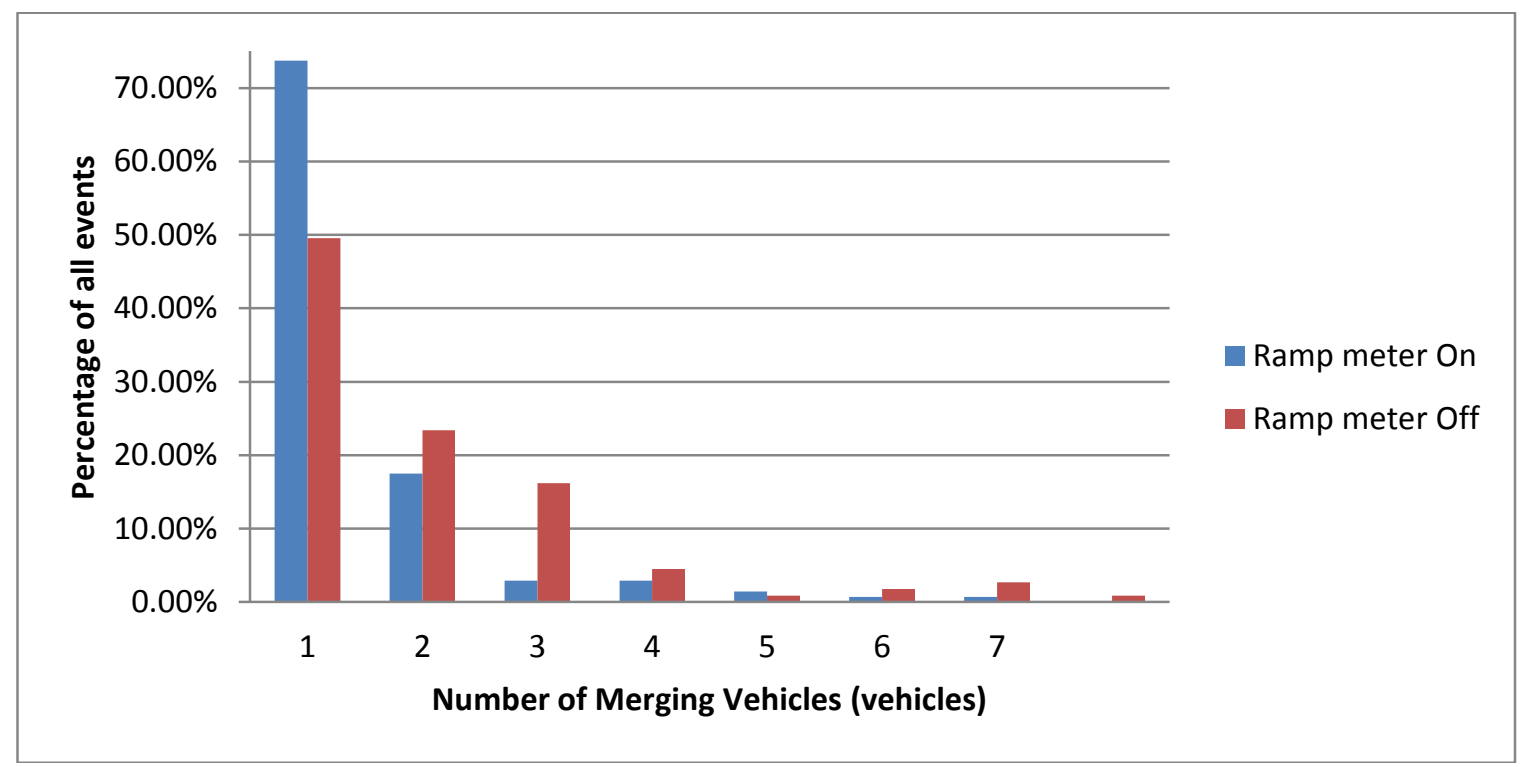

Figure 4.3 Frequency of multi-vehicle merges.

\subsection{Mobility Results}

The amount of delay experienced by mainline and ramp vehicles with and without ramp meter were analyzed using simulations. In Table 4.25, mainline delay, ramp delay, and total delay (mainline plus ramp) are shown for six volume scenarios. Each volume scenario consists of a different truck percentage with mainline and ramp volumes as described in section 3.2, Mobility Analysis. For ramp delays, ramp vehicles were tracked from the time they arrive on the ramp until they travel past the work zone taper. Thus, ramp delay with ramp meter includes the wait time at the signal and any travel delays occurring on the mainline between ramp entrance and the work zone taper. The percent change in delay was computed as the delay with ramp meter minus the delay without ramp meter divided by the delay with ramp meter. Accordingly, a positive change indicates that ramp meter increased the delay and a negative change indicates a decrease in delay due to ramp meter deployment. The percent changes for ramp vehicles and mainline vehicles are shown in Tables 4.26 and 4.27, respectively. 
Table 4.25 Mainline and Ramp Delays with and without Ramp Meter for all Work Zones

\begin{tabular}{|c|c|c|c|c|c|c|c|}
\hline \multirow[b]{2}{*}{ I-70/Providence } & \multirow[b]{2}{*}{ Truck \% } & \multicolumn{2}{|c|}{ Under Capacity } & \multicolumn{2}{|c|}{ Capacity } & \multicolumn{2}{|c|}{ Above Capacity } \\
\hline & & $10 \%$ & $40 \%$ & $10 \%$ & $40 \%$ & $10 \%$ & $40 \%$ \\
\hline \multirow{3}{*}{ With Ramp Meter } & Mainline Delay (Hours) & 1.7 & 2.3 & 4.6 & 12.5 & 65.8 & 104.4 \\
\hline & Ramp Delay (Hours) & 0.7 & 0.9 & 1.8 & 4.8 & 34.5 & 44.1 \\
\hline & Total Delay (Hours) & 2.5 & 3.1 & 6.4 & 17.3 & 100.3 & 148.5 \\
\hline \multirow{3}{*}{ Without Ramp Meter } & Mainline Delay (Hours) & 1.6 & 2.1 & 4.8 & 12.7 & 77.8 & 108.8 \\
\hline & Ramp Delay (Hours) & 0.3 & 0.3 & 0.9 & 4.0 & 37.8 & 43.1 \\
\hline & Total Delay (Hours) & 1.8 & 2.4 & 5.7 & 16.7 & 115.6 & 151.9 \\
\hline \multicolumn{8}{|l|}{ I-70/West } \\
\hline \multirow{3}{*}{ With Ramp Meter } & Mainline Delay (Hours) & 0.5 & 0.8 & 2.5 & 22.0 & 53.5 & 55.1 \\
\hline & Ramp Delay (Hours) & 0.7 & 0.7 & 1.7 & 9.0 & 20.9 & 31.6 \\
\hline & Total Delay (Hours) & 1.2 & 1.5 & 4.2 & 31.0 & 74.5 & 86.8 \\
\hline \multirow{3}{*}{ Without Ramp Meter } & Mainline Delay (Hours) & 0.4 & 0.8 & 2.7 & 21.9 & 62.2 & 59.1 \\
\hline & Ramp Delay (Hours) & 0.1 & 0.2 & 0.9 & 8.3 & 29.5 & 31.0 \\
\hline & Total Delay (Hours) & 0.5 & 1.0 & 3.6 & 30.2 & 91.7 & 90.1 \\
\hline \multicolumn{8}{|l|}{ I-70/US 63} \\
\hline \multirow{3}{*}{ With Ramp Meter } & Mainline Delay (Hours) & 2.8 & 3.4 & 7.4 & 10.4 & 48.7 & 65.1 \\
\hline & Ramp Delay (Hours) & 0.8 & 0.9 & 2.0 & 2.9 & 25.7 & 33.1 \\
\hline & Total Delay (Hours) & 3.6 & 4.4 & 9.4 & 13.2 & 74.3 & 98.2 \\
\hline \multirow{3}{*}{ Without Ramp Meter } & Mainline Delay (Hours) & 0.9 & 1.0 & 3.8 & 9.5 & 69.0 & 81.4 \\
\hline & Ramp Delay (Hours) & 0.3 & 0.4 & 1.4 & 4.5 & 29.6 & 35.5 \\
\hline & Total Delay (Hours) & 1.2 & 1.4 & 5.2 & 14.0 & 98.6 & 117.0 \\
\hline \multicolumn{8}{|c|}{ US 63/Stad. (Left lane closed) } \\
\hline \multirow{3}{*}{ With Ramp Meter } & Mainline Delay (Hours) & 0.4 & 0.6 & 1.7 & 18.0 & 70.2 & 72.0 \\
\hline & Ramp Delay (Hours) & 0.6 & 0.6 & 1.4 & 7.4 & 32.9 & 32.4 \\
\hline & Total Delay (Hours) & 1.0 & 1.2 & 3.1 & 25.4 & 103.1 & 104.4 \\
\hline \multirow{3}{*}{ Without Ramp Meter } & Mainline Delay (Hours) & 0.4 & 0.5 & 1.5 & 16.2 & 83.3 & 79.1 \\
\hline & Ramp Delay (Hours) & 0.1 & 0.2 & 0.5 & 4.8 & 21.9 & 46.9 \\
\hline & Total Delay (Hours) & 0.5 & 0.6 & 2.0 & 21.0 & 105.2 & 126.0 \\
\hline \multicolumn{8}{|c|}{ US 63/Stad. (Right lane closed) } \\
\hline \multirow{3}{*}{ With Ramp Meter } & Mainline Delay (Hours) & 0.35 & 0.51 & 1.82 & 20.21 & 66.11 & 59.30 \\
\hline & Ramp Delay (Hours) & 0.55 & 0.62 & 1.54 & 8.10 & 26.56 & 35.82 \\
\hline & Total Delay (Hours) & 0.90 & 1.13 & 3.37 & 28.31 & 92.67 & 95.12 \\
\hline \multirow{3}{*}{ Without Ramp Meter } & Mainline Delay (Hours) & 0.35 & 0.48 & 1.71 & 17.81 & 73.48 & 77.73 \\
\hline & Ramp Delay (Hours) & 0.14 & 0.17 & 0.57 & 6.42 & 29.87 & 63.43 \\
\hline & Total Delay (Hours) & 0.49 & 0.65 & 2.27 & 24.23 & 103.35 & 141.16 \\
\hline
\end{tabular}


Table 4.26 Change in Ramp Delay Due to Ramp Metering

\begin{tabular}{|c|c|c|c|c|c|c|c|c|}
\hline & \multirow{2}{*}{$\begin{array}{c}\text { Total volume } \\
\text { (mainline } \\
\text { ramp) }\end{array}$} & Truck \% & I-70/ & $\begin{array}{c}\text { I-70/ } \\
\text { West }\end{array}$ & $\begin{array}{c}\text { I-70/ } \\
\text { US 63 }\end{array}$ & $\begin{array}{c}\text { US-63/ } \\
\text { Std. } \\
\text { (Left) }\end{array}$ & $\begin{array}{c}\text { US-63/ } \\
\text { Std. } \\
\text { (Right) }\end{array}$ & Ave. \\
\hline \multirow{2}{*}{ Under capacity } & $\begin{array}{c}900 \\
(650+250)\end{array}$ & Low (10\%) & $64 \%$ & $80 \%$ & $61 \%$ & $77 \%$ & $75 \%$ & $71 \%$ \\
\cline { 3 - 9 } & & High (40\%) & $62 \%$ & $74 \%$ & $57 \%$ & $72 \%$ & $72 \%$ & $67 \%$ \\
\hline \multirow{2}{*}{ At Capacity } & 1240 & Low (10\%) & $50 \%$ & $49 \%$ & $30 \%$ & $60 \%$ & $63 \%$ & $50 \%$ \\
\cline { 3 - 9 } & $(900+340)$ & High (40\%) & $16 \%$ & $7 \%$ & $-59 \%$ & $36 \%$ & $21 \%$ & $4 \%$ \\
\hline \multirow{2}{*}{ Above capacity } & 1754 & Low (10\%) & $-10 \%$ & $-41 \%$ & $-15 \%$ & $33 \%$ & $-12 \%$ & $-9 \%$ \\
\cline { 3 - 9 } & $(1240+514)$ & High (40\%) & $2 \%$ & $2 \%$ & $-7 \%$ & $-45 \%$ & $-77 \%$ & $-25 \%$ \\
\hline
\end{tabular}

Table 4.27 Change in Mainline Delay Due to Ramp Metering

\begin{tabular}{|c|c|c|c|c|c|c|c|c|}
\hline & \multirow{2}{*}{$\begin{array}{c}\text { Total volume } \\
\text { (mainline } \\
\text { ramp) }\end{array}$} & Truck \% & I-70/ & $\begin{array}{c}\text { I-70/ } \\
\text { West }\end{array}$ & $\begin{array}{c}\text { I-70/ } \\
\text { US 63 }\end{array}$ & $\begin{array}{c}\text { US-63/ } \\
\text { Std. } \\
\text { (Left) }\end{array}$ & $\begin{array}{c}\text { US-63/ } \\
\text { Std. } \\
\text { (Right) }\end{array}$ & Ave. \\
\hline \multirow{2}{*}{ Under capacity } & $\begin{array}{c}900 \\
(650+250)\end{array}$ & Low (10\%) & $10 \%$ & $33 \%$ & $69 \%$ & $17 \%$ & $0 \%$ & $26 \%$ \\
\cline { 3 - 9 } & & High (40\%) & $8 \%$ & $-2 \%$ & $70 \%$ & $15 \%$ & $7 \%$ & $19 \%$ \\
\hline \multirow{2}{*}{ At Capacity } & 1240 & Low (10\%) & $-5 \%$ & $-11 \%$ & $48 \%$ & $14 \%$ & $6 \%$ & $11 \%$ \\
\cline { 3 - 9 } & $(900+340)$ & High (40\%) & $-1 \%$ & $1 \%$ & $9 \%$ & $10 \%$ & $12 \%$ & $6 \%$ \\
\hline \multirow{2}{*}{ Above capacity } & 1754 & Low (10\%) & $-18 \%$ & $-16 \%$ & $-42 \%$ & $-19 \%$ & $-11 \%$ & $-21 \%$ \\
\cline { 3 - 9 } & $(1240+514)$ & High (40\%) & $-4 \%$ & $-7 \%$ & $-25 \%$ & $-10 \%$ & $-31 \%$ & $-15 \%$ \\
\hline
\end{tabular}

For under capacity conditions, Tables 4.26 and 4.27 show increases in mainline and ramp delay due to ramp metering, except for a slight decrease of $2 \%$ at I-70/West site for $40 \%$ trucks. The percentage delay increase for ramp traffic was about three times that of the mainline traffic. Thus, for under capacity conditions ramp metering adversely affected ramp traffic by producing approximately $70 \%$ additional delay. For at capacity conditions, metering increased ramp delay at all sites for low truck volume conditions. For high truck volume conditions delay increased on all ramps except the I-70/US 63 ramp. The delay changes on mainline for at capacity conditions were not uniform, with two sites exhibiting a decrease and three sites exhibiting an increase due to metering. This is possibly due to the traffic flow transitioning from under capacity, where the ramp metering increased delays, to above capacity conditions, where metering decreased delays. For above capacity conditions, the mainline delays decreased at all locations for both low and high truck percentages when ramp metering was deployed. The ramp delays decreased in most situations except for three cases: 33\% increase at Stadium/US 63 site with left lane closure for $10 \%$ trucks, and negligible increases at I-70/Providence and I-70/West locations for $40 \%$ trucks. Despite these exceptions, the overall pattern supports the assertion that ramp metering reduces total delay when volumes are above capacity.

The percentage change was averaged across all locations separately for ramp and mainline and shown in the final column of Table 4.26 and Table 4.27, respectively. For under capacity conditions, ramp delay $(+71 \%$ for Low and $+67 \%$ for High) and mainline delay increased ( $+26 \%$ for Low and $+19 \%$ for High) due to ramp metering. Similar trend occurred for at capacity conditions, both ramp delay ( $+50 \%$ for Low and $+4 \%$ for High) and mainline delay increased ( $+11 \%$ for Low and $+6 \%$ for High) due to ramp metering. However, for above capacity 
conditions ramp metering decreased the average delay for both ramp (-9\% for Low and $-25 \%$ for High) and mainline (-21\% for Low and $-15 \%$ for High).

The results of changes in total delay combining both mainline and ramp vehicles are shown in Table 4.28.

Table 4.28 Change in Total Delay Due to Ramp Metering

\begin{tabular}{|c|c|c|c|c|c|c|c|c|}
\hline & \multirow{2}{*}{$\begin{array}{c}\text { Total volume } \\
\text { (mainline } \\
\text { ramp) }\end{array}$} & Truck \% & \multicolumn{6}{|c|}{ Work Zone Location } \\
\cline { 4 - 9 } & & & $\begin{array}{c}\text { I-70/ } \\
\text { Prov. }\end{array}$ & $\begin{array}{c}\text { I-70/ } \\
\text { West }\end{array}$ & $\begin{array}{c}\text { I-70/ } \\
\text { US 63 }\end{array}$ & $\begin{array}{c}\text { US-63/ } \\
\text { Std. } \\
\text { (Left) }\end{array}$ & $\begin{array}{c}\text { US-63/ } \\
\text { Std. } \\
\text { (Right) }\end{array}$ & Ave. \\
\hline \multirow{2}{*}{ Under capacity } & $\begin{array}{c}900 \\
(650+250)\end{array}$ & Low (10\%) & $26 \%$ & $59 \%$ & $67 \%$ & $52 \%$ & $46 \%$ & $50 \%$ \\
\cline { 3 - 9 } & & High (40\%) & $22 \%$ & $35 \%$ & $67 \%$ & $45 \%$ & $42 \%$ & $42 \%$ \\
\hline \multirow{2}{*}{ At Capacity } & 1240 & Low (10\%) & $10 \%$ & $14 \%$ & $44 \%$ & $35 \%$ & $33 \%$ & $27 \%$ \\
\cline { 3 - 9 } & $(900+340)$ & High (40\%) & $4 \%$ & $3 \%$ & $-6 \%$ & $17 \%$ & $14 \%$ & $6 \%$ \\
\hline \multirow{2}{*}{ Above capacity } & 1754 & Low (10\%) & $-15 \%$ & $-23 \%$ & $-33 \%$ & $-2 \%$ & $-12 \%$ & $-24 \%$ \\
\cline { 3 - 9 } & $(1240+514)$ & High (40\%) & $-2 \%$ & $-4 \%$ & $-19 \%$ & $-21 \%$ & $-48 \%$ & $-19 \%$ \\
\hline
\end{tabular}

For under capacity conditions, ramp metering increased the total delay at all sites. This trend continued for at capacity conditions with the exception of one site for high truck volume. For traffic volumes exceeding capacity conditions, ramp metering decreased total delay for both low and high truck volumes at all sites. Thus metering of ramps will improve the mobility at work zone sites that experience traffic volumes greater than the work zone-reduced capacities. On average a $24 \%$ decrease in delay at low truck percentage and a $19 \%$ decrease in delay at high truck percentage conditions resulted from metering ramps near work zones operating above capacity.

The effect of ramp metering in a work zone with left lane closure versus a work zone with right lane closure can be seen in Table 4.28. For the US-63/Stadium work zones, the percentage changes in total delay for under capacity and at capacity conditions were similar for left and right lane closures. For above capacity conditions, greater delay savings were observed at the right lane closed site when compared with the left lane closed site. This difference was magnified for high truck volume conditions. One possible reason for this difference is that the right lane closure scenario has more gaps for the merging ramp traffic, since the ramp traffic merges onto the closed right lane first. In the left lane closure scenario, both the mainline and the ramp traffic are funneled into the same lane, and the platoon-breaking benefits of ramp metering are less effective. 


\section{CONCLUSIONS}

This evaluation suggests that temporary ramp meters should only be deployed at locations where there is potential for congestion and turned on only during periods when demand exceeds capacity. The drawbacks outweigh the minor benefits when the ramp meter is used for noncongested conditions. The compliance rate is relatively low (e.g. 63.6\%) when there are few vehicles on the ramps. And under such conditions, the objective of breaking up platoons of merging vehicles is not achieved since there are no ramp vehicle platoons. Under non-congested conditions, ramp speeds are reduced significantly (e.g. $-19.5 \%$ ), resulting in increases in both mainline speed variance (e.g. $+29 \%$ ) and speed differential between merging vehicle and mainline vehicle (e.g. $+98.67 \%$ ). Under congested conditions, the mainline speeds are much lower thus such drawbacks do not appear. Even under non-congested conditions, ramp meters beneficially shift the frequency distribution of merging platoons towards smaller platoon sizes.

The compliance analysis showed that lack of compliance could be a major safety issue in the deployment of temporary ramp meters. The lack of compliance could occur due to three possible reasons: 1) the temporary nature of such deployments could catch drivers by surprise, 2) the ramp designs may not be ideal for ramp metering, and 3) the driver population in the study location may not be familiar with freeway ramp metering. These three reasons are not mutually exclusive. The use of a three-section signal head instead of a traditional two-section ramp signal head used produced significantly higher compliance rates. This finding could be attributed to the familiarity of drivers with the three-section signal head at intersections. Thus, the use of a threesection signal head is recommended for temporary ramp meter deployments in work zones, especially at locations where driving population is not familiar with ramp metering.

Mobility analysis revealed that ramp metering produced delay savings for both mainline and ramp vehicles for work zones operating above capacity. On average a $24 \%$ decrease in total delay (mainline plus ramp) at low truck percentage and a 19\% decrease in delay at high truck percentage conditions resulted from ramp metering. For flows below capacity, ramp metering is not recommended since it increased delays in most scenarios. Ramp metering was also found to provide greater mobility benefits at two-to-one lane work zones with a right lane closure as compared to a left lane closure. Additional field studies are needed to validate this finding.

Because this was the first field deployment of a temporary ramp meter, MoDOT had concerns about deploying ramp meters in highly congested areas. To minimize traffic impacts, MoDOT avoids closing lanes during peak hours in urban areas. Although all deployments in this study were in an urban area, they were conducted during off-peak hours. Future research could add to the existing study by including highly congested field sites. 


\section{ACKNOWLEDGMENTS}

This research was conducted under the Midwest Smart Work Zone Deployment Initiative (SWZDI) and Federal Highway Administration (FHWA) Pooled Fund Study TPF-5(081), involving the following state departments of transportation:

- Iowa (lead state)

- Kansas

- Missouri

- Nebraska

- Wisconsin

The authors would like to express their gratitude to the FHWA, the Iowa Department of Transportation (DOT), and the other pooled fund state partners for their financial support and technical assistance.

The authors are thankful for the assistance provided by MoDOT staff Dan Smith and Ken Strube for coordinating field data collection sites. The authors wish to acknowledge the contributions of Ryan Holmes, Jalil Kianfar, Yi Hou, and Yang Song, who helped with data collection and analysis, and Audrey Freiberger, Peng Yu, Chris Adrian who assisted with the data processing, and Naghma Hassan who helped with the VISSIM simulation models. 


\section{REFERENCES}

1. Toorawa, M. and W. Ireij, 2004 Ramp Metering Annual Report: District 07, Los Angeles and Ventura Counties. California Department of Transportation, 2005.

2. Cambridge Systematics, Incorporated. Twin Cities Ramp Meter Evaluation - Final Report. Minnesota Department of Transportation, 2001.

3. Cambridge Systematics, Incorporated. Twin Cities Ramp Meter Evaluation: Phase II. Minnesota Department of Transportation, 2002.

4. Lee, C., B. Hellinga, and K. Ozbay. Quantifying the Effects of Ramp Metering on Freeway Safety. Accident Analysis and Prevention, Vol. 38, No. 2, 2006, pp. 279-288.

5. Lee, C., F. Saccomanno and B. Hellinga. Analysis of Crash Precursors on Instrumented Freeways. In Transportation Research Record: Journal of the Transportation Research Board, No. 1784, Transportation Research Board of the National Academies, Washington, D.C., 2002, pp. 1-8.

6. Dhindsa, A. Evaluating Ramp Metering and Variable Speed Limits to Reduce Crash Potential on Congested Freeways Using Micro-Simulation. Master's Thesis, University of Central Florida, Orlando, 2006

7. Abdel-Aty, M. and V. Gayah. Real-Time Crash Risk Reduction on Freeways Using Coordinated and Uncoordinated Ramp Metering Approaches. Journal of Transportation Engineering, Vol. 136, No. 2, 2010, pp. 410-423.

8. Manual of Uniform Traffic Control Devices, 2009 Edition. FHWA, U.S. Department of Transportation, 2009.

9. Jacobson, L., J. Stribiak, L. Nelson and D. Sallman. Ramp Management and Control Handbook. Publication FHWA-HOP-06-001. FHWA, U.S. Department of Transportation, Jan. 2006.

10. A Policy on Geometric Design of Highways and Streets. 5th Edition. American Association of State Highway and Transportation Officials, Washington, D.C., 2004.

11. Milton, J. S., and J. C. Arnold. Introduction to probability and statistics: principles and applications for engineering and the computing science. McGraw-Hill, Inc., 1995.

12. Highway Capacity Manual 2010. Transportation Research Board of the National Academies, Washington, D.C., 2010.

13. Edara, P., J. Kianfar, C. Sun. Analytical Methods for Deriving Work Zone Capacities from Field Data. ASCE Journal of Transportation Engineering, Vol. 138, No. 6, 2012, pp. 809818.

14. TXDOT, Traffic Data and Analysis Manual. Texas Department of Transportation, 2001. onlinemanuals.txdot.gov/txdotmanuals/tda/tda.pdf. Accessed Jul. 29, 2012.Kansas City 